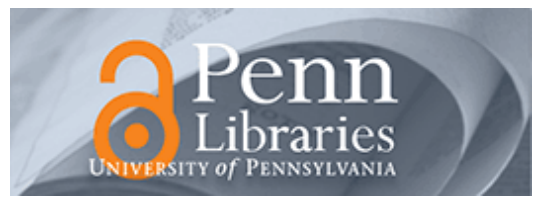

University of Pennsylvania ScholarlyCommons

2013

\title{
How Much Do Investors Care About Macroeconomic Risk? Evidence From Scheduled Economic Announcements
}

Pavel Savor

University of Pennsylvania

Mungo Wilson

Follow this and additional works at: https://repository.upenn.edu/fnce_papers

Part of the Finance and Financial Management Commons, and the Management Sciences and Quantitative Methods Commons

\section{Recommended Citation}

Savor, P., \& Wilson, M. (2013). How Much Do Investors Care About Macroeconomic Risk? Evidence From Scheduled Economic Announcements. Journal of Financial and Quantitative Analysis, 48 (2), 343-375. http://dx.doi.org/10.1017/S002210901300015X 


\title{
How Much Do Investors Care About Macroeconomic Risk? Evidence From Scheduled Economic Announcements
}

\author{
Abstract \\ Stock market average returns and Sharpe ratios are significantly higher on days when important \\ macroeconomic news about inflation, unemployment, or interest rates is scheduled for announcement. \\ The average announcement-day excess return from 1958 to 2009 is 11.4 basis points (bp) versus $1.1 \mathrm{bp}$ \\ for all the other days, suggesting that over $60 \%$ of the cumulative annual equity risk premium is earned on \\ announcement days. The Sharpe ratio is 10 times higher. In contrast, the risk-free rate is detectably lower \\ on announcement days, consistent with a precautionary saving motive. Our results demonstrate a trade- \\ off between macroeconomic risk and asset returns, and provide an estimate of the premium investors \\ demand to bear this risk.

\section{Disciplines} \\ Finance and Financial Management | Management Sciences and Quantitative Methods
}




\title{
How Much Do Investors Care About Macroeconomic Risk? Evidence From Scheduled Economic Announcements
}

\author{
Pavel Savor \\ The Wharton School, University of Pennsylvania \\ psavor@wharton.upenn.edu \\ (215) 898-7543 \\ Mungo Wilson \\ Said Business School, Oxford University; Oxford-Man Institute \\ Mungo.Wilson@sbs.ox.ac.uk
}

We thank the editor, Hendrik Bessembinder, two anonymous referees, Michael Brennan, John Campbell, George Constantinides, Pierre Collin-Dufresne, Gene Fama, Charles Jones, Juhani Linnainmaa, Ralph Koijen, Michael Lemmon, Jose Martinez, Lubos Pastor, Michael Roberts, Stephanie Sikes, Costis Skiadas, Pietro Veronesi, Amir Yaron, and seminar participants at Binghamton University, Exeter University, the Federal Reserve Bank of New York, Hong Kong University of Science and Technology, Imperial College, INSEAD, Kepos Capital, London School of Economics, Oxford University, SAC Capital, the University of Chicago, the University of Pennsylvania, Warwick Business School, 2008 Adam Smith Asset Pricing Conference, 2010 Eastern Finance Association Annual Meeting, 2010 Rothschild Caesarea Center Annual Academic Conference, and 2010 Utah Winter Finance Conference for their valuable comments. Savor gratefully acknowledges financial support from the Rodney L. White Center. Wilson gratefully acknowledges the financial support from the Oxford-Man Institute and the Research Grants Council of Hong Kong (Grant No. HKUST6478/06H). 


\begin{abstract}
Stock market average returns and Sharpe ratios are significantly higher on days when important macroeconomic news about inflation, unemployment, or interest rates is scheduled for announcement. The average announcement day excess return from 1958 to 2009 is 11.4 basis points versus 1.1 basis points for all the other days, suggesting that over $60 \%$ of the cumulative annual equity risk premium is earned on announcement days. The Sharpe ratio is ten times higher. In contrast, the risk-free rate is detectably lower on announcement days, consistent with a precautionary saving motive. Our results demonstrate a trade-off between macroeconomic risk and asset returns, and provide an estimate of the premium investors demand to bear this risk.
\end{abstract}




\section{Introduction}

The link between macroeconomic risk and security returns is central to financial economics. While a lot of relevant information about the economy arrives randomly over time, certain important macroeconomic news is released in the form of pre-scheduled announcements, whose dates are known months in advance. Investors do not know what the news will be, but they do know that there will be news. If asset prices respond to this news, the risk associated with holding securities will be higher around announcements, and this will be anticipated by rational investors.

An extensive prior literature, which we discuss below, presents evidence consistent with a higher conditional risk of holding financial assets ahead of macroeconomic announcements. Risk-averse investors who know that they will be exposed to higher risk should demand, and in equilibrium receive, a higher expected excess return during those times (provided that this risk is priced by investors as a group). Stock returns should thus be predictably higher on announcement days, and this is the main hypothesis we explore in this paper (rather than studying the impact of announcement surprises on realized returns). For example, if investors prefer to avoid inflation risk, then times of inflation announcements must be times of higher average excess returns over a sufficiently long time period (one in which the average surprise equals zero).

Consistent with this general idea, we find that average U.S. stock market returns from 1958 to 2009 are significantly higher on days when important macroeconomic news is scheduled to be announced. On days when the Consumer Price Index (CPI), Producer Price Index (PPI), employment figures or Federal Open Market Committee (FOMC) decisions are released, excess market returns average 11.4 basis points (bps) versus only 1.1 bps for all the other days. These figures imply that compensation for bearing macroeconomic announcement risk accounts for a large portion of the equity risk premium, as over $60 \%$ of the cumulative annual excess return is earned on just $13 \%$ of the trading days, whose timing is known to investors well in advance. Conversely, the risk premium for holding stocks at other times is very low, 
with the average excess return on those days not being statistically distinguishable from zero. $^{1}$

Despite this evidence of a significantly higher announcement day risk premium, we find that the realized volatility of daily stock market returns is only $4 \%$ higher. The effect on implied volatility is larger than for realized volatility, but the magnitudes are still much lower than those for the difference in returns. The stock market's realized Sharpe ratio is therefore ten times higher on announcement days; a myopic investor would need to exhibit implausibly high risk aversion in order to account for this difference.

One explanation consistent with our results requires a positive dependence of stock market returns on state variables such as expected long-run economic growth and inflation. Intuitively, stocks tend to perform particularly poorly when news about the state of the economy is negative, making them much riskier than just their volatility would suggest. Given that scheduled economic announcements presumably reveal important information about the economy, this state variable risk should be deterministically higher at such times. ${ }^{2}$ Risk premia can therefore increase on announcement days, even if conditional volatility does not change. This explanation can reconcile the large announcement effect on risk premia with the small effect on observed return volatility and the corresponding difference in Sharpe ratios. Intriguingly, it implies that the major component of the equity premium is compensation for exposure to news about the state of the economy: macroeconomic risk.

This argument also suggests that periods of high uncertainty about the direction of the economy should be times when the difference between announcement and non-announcement day returns is especially high, and we confirm this hypothesis. We estimate that a doubling of stock market variance increases the differential by $60 \%$.

\footnotetext{
${ }^{1} \mathrm{By}$ contrast, we find that the average excess return on days of unscheduled FOMC announcements is strongly negative (-89.2 bps for 15 such days between 2001 and 2009). This is consistent with the prescheduled nature of the announcements in our tests being the crucial characteristic driving differences in risk premia.

${ }^{2}$ In support of this hypothesis, we find that in the second half of our sample period announcement day returns predict consumption growth significantly better than non-announcement returns.
} 
Higher risk on announcement days should also affect the risk-free rate. Increased risk can raise desired saving by risk-averse investors to insure against adverse states of the world. In equilibrium, increased precautionary saving demand should reduce returns on the risk-free asset, and we find strong support for this prediction. The average holding period return on 30-day U.S. Treasury bills (our proxy for the daily risk-free rate) is 0.7 bps lower on announcement days, relative to the sample mean of $2.2 \mathrm{bps}$, with a $t$-statistic of above 10 .

For longer-term Treasury securities, which are not riskless assets at a daily horizon, the difference between average announcement and non-announcement day returns increases monotonically with a bond's maturity, as we would predict if investors expect higher returns on riskier assets on announcement days. Treasury bonds with maturities over one year behave similarly to the stock market, with higher excess returns, similar volatilities, and consequently significantly higher Sharpe ratios on announcement days relative to non-announcement days.

Our results hold over the full 1958-2009 sample (1961-2009 for Treasuries), are almost unchanged in various subsamples, are robust to exclusion of outliers, and hold separately for each type of announcement. They are also not explained by various calendar anomalies, including the January effect, the day-of-the-week effect (French (1980), Gibbons and Hess (1981)), the turn-of-the-month effect (Ariel (1987), Lakonishok and Smidt (1988)), the firsthalf-of-the-month effect (Ariel (1987)), the holiday effect (Ariel (1990)), and seasonality induced by payment lags (Flannery and Protopapadakis (1988)).

It is possible that the post-war period in the U.S. was an unusually good time for equities, with economic growth consistently beating expectations and a benign inflation experience. If these unexpectedly favorable developments were revealed primarily through scheduled announcements, this could explain our finding that stock returns on announcement days are significantly higher. ${ }^{3}$ However, our results remain the same if we include controls for announcement surprises, which we either estimate directly or compute using forecasts by the Society of Professional Forecasters. Furthermore, the announcement day premium is present

\footnotetext{
${ }^{3} \mathrm{An}$ analagous argument can be made for long-term bonds.
} 
in nine out of ten five-year subsamples starting in 1958, some of which do not seem to coincide with positive economic conditions.

A number of papers investigate the sensitivity of realized returns to the news component of scheduled macroeconomic announcements. For instance, a positive inflation shock (an announcement of an inflation number higher than the market expectation) may induce a negative contemporaneous stock market return. In the language of factor models, these papers investigate factor betas as opposed to factor risk premia. Formally, given an announcement day surprise $z_{t+1}$, defined as the difference between the announced number and its forecast, a test asset return $r_{t+1}$ is decomposed into its conditional expectation and its residual:

$$
r_{t+1}=E_{t}\left[r_{t+1}\right]+\beta z_{t+1}+\varepsilon_{t+1} .
$$

Starting with Schwert (1981), Pearce and Roley (1983), Pearce and Roley (1985), Hardouvelis (1987), Cutler, Poterba, and Summers (1989), Orphanides (1992), McQueen and Roley (1993), Krueger (1996), Fleming and Remolona (1997), Balduzzi, Elton, and Green (2001), Bomfim (2003), and Gurkaynak, Sack, and Swanson (2005) study the responsiveness $\beta$ of stock or bond returns to various macroeconomic shocks $z_{t+1}$. More recently, Boyd, $\mathrm{Hu}$, and Jagannathan (2005) explore the sensitivity of security returns to unemployment surprises, and find a positive stock market response to news of rising unemployment during economic expansions (a positive $\beta$ ) and a negative response during contractions (a negative $\beta$ ). Andersen, Bollerslev, Diebold, and Vega (2007) use a high-frequency futures data set and get a similar result that the stock market response to macroeconomic news depends on general economic conditions. Bernanke and Kuttner (2005) analyze the impact of FOMC interest rate announcement surprises on stock market returns.

Flannery and Protopapadakis (2002) estimate a direct announcement effect on contemporaneous returns through the sensitivity to announcement news $\beta$ together with an indirect effect through higher conditional volatility of shocks $\varepsilon_{t+1}$ (even if $\beta$ equals zero) on announcement days. They employ a GARCH model to identify which macroeconomic surprises (out of 
17 candidates) influence realized equity returns or their conditional volatility. They come up with three variables (CPI, PPI, and the monetary aggregate) for which there exists a relation between surprises and returns, and only one of those (the monetary aggregate) affects returns both directly and indirectly.,

By contrast, this study focuses on the effect of pre-scheduled announcements on expected returns $E_{t}\left[r_{t+1}\right]$. We identify the magnitude of the difference between expected returns on announcement days versus expected returns on other days for the stock market, long-term bonds, and T-bills. As a consequence, we are not directly interested in the announcement surprise $z_{t+1}$ but rather in the average realized return over a long sample. This means we do not need to make assumptions about market expectations for a given variable or even about what exactly constitutes good or bad news at any particular point in time. ${ }^{6}$ We also do not need to know the size or sign of $\beta$, as long as we accept the results of the earlier studies that find that $\beta$ is different from zero, and therefore announcement days are periods of higher systematic risk. Jones, Lamont, and Lumsdaine (1998) adopt a methodology similar to ours and find that both the mean excess returns for long-term Treasury bonds and their volatilities are higher on PPI and employment announcement days. ${ }^{7}$

Our results could be related to the well-known phenomenon of high average stock returns

\footnotetext{
${ }^{4}$ The finding that unexpected inflation and money growth negatively affect stock prices is not new. See Bodie (1976), Nelson (1976), Fama and Schwert (1977), Jaffe and Mandelker (1979), Fama (1987), Schwert (1981), Geske and Roll (1983), Pearce and Roley (1983), and Pearce and Roley (1985) for previous studies establishing this relation.

${ }^{5}$ Brenner, Pasquariello, and Subrahmanyam (2009) estimate a similar GARCH framework for stock, Treasury, and corporate bond markets that allows for an announcement day effect on the mean through a variance-in-mean channel, but find no evidence of a positive statistically significant effect on average excess returns.

${ }^{6}$ It is not always obvious how the market will interpret a particular macroeconomic shock. For example, if the stock market response to news of rising unemployment depends on concurrent economic conditions, a lower than anticipated number could represent bad news. Similarly, lower than expected inflation in Japan in recent years was not necessarily good news for investors.

${ }^{7}$ We document a similar result in our sample.
} 
for firms announcing earnings. This earnings announcement premium was first discovered by Beaver (1968) and was subsequently confirmed by Chari, Jagannathan, and Ofer (1988), Ball and Kothari (1991), Cohen, Dey, Lys, and Sunder (2007), Frazzini and Lamont (2007), and Savor and Wilson (2011), who all find that the above-average returns around earnings announcement days do not appear to be explained by increases in risk. Kalay and Loewenstein (1985) obtain the same finding for firms announcing dividends. While potentially similar, our results are easier to interpret in the framework of a rational choice equilibrium, since we do not need to distinguish between the idiosyncratic component of announcement day risk and the systematic component. It is not immediately clear to what extent firm-level announcement risk can be diversified away, but macroeconomic announcement risk surely cannot be diversified to any significant extent.

Our explanation for the documented announcement day premia focuses on a risk-return trade-off that compensates investors for higher macroeconomic risk around announcement days. An interesting alternative possibility is that even myopic investors effectively become more risk-averse ahead of announcements, resulting in a higher price of stock market variance. Such investors could be averse to uncertainty in the sense proposed by Knight (1921). With an announcement approaching, their utility functions become more concave as the worst possible distributions of outcomes receive higher weights. ${ }^{8}$ Other potential explanations include the changing composition of investors participating in stocks and T-bills ahead of announcements, which would alter the risk aversion of the representative investor, or an irrationally excessive investor aversion to announcement risk.

The rest of the paper is organized as follows: Section II presents a simple model deriv-

${ }^{8}$ Skiadas (2008) shows that for small risks (a large probability of a small change or a small probability of a large change) many of the preferences in the current literature are, to a first-order approximation, equivalent to expected utility or Kreps-Porteous recursive preferences, so that ambiguity aversion need have no first-order effects on asset prices when risks are small. Pre-scheduled announcements, however, are the quintessential large risk: they are events involving the near certainty of a non-negligible change (even if zero-mean). Thus, even standard ambiguity aversion can deliver higher risk prices ahead of announcements. 
ing all of our main predictions; Section III reports our principal results and relates them to our model; Section IV shows additional supporting evidence; and Section V concludes. Derivations of our propositions are given in the Appendix.

\section{Announcement Risk in an Endowment Economy}

Our intuition is that times around scheduled macroeconomic news announcements are periods of foreseeably higher systematic risk, and that consequently expected excess returns on risky assets should be higher during those periods. In equilibrium, this intuition can also imply that risk-free rates should be lower during the same periods. Here we analyze this idea in a formal model of scheduled announcements in an endowment economy with a single Lucas tree and a single representative investor with recursive preferences, in which inflation and real interest rates are stochastic. All derivations are placed in the Appendix.

The central idea of our model is that investors learn more about the state of the economy on announcement days than on other days. Investors are rewarded not just for bearing market risk but also state variable risk, which we define as the risk of learning that the economy is performing worse than expected. Consequently, risky assets whose returns have high covariance with the state variable can earn much higher risk premia around announcements, even if the volatility of their returns is not very different. Such assets include the overall stock market and long-term nominal bonds. Since these assets' returns have a larger common component on announcement days, they should comove more around announcements. The model shows how this idea can be made consistent with general equilibrium by equating the state variable in the Intertemporal Capital Asset Pricing Model of Merton (1973) with long-term expected consumption growth in an endowment economy, as in Bansal and Yaron (2004).

The primary purpose of the model is to demonstrate that all of the announcement effects we document are consistent with a rational expectations equilibrium. The model also makes it easier to understand which forces may be driving our findings and suggests additional 
testable hypotheses. Most of our empirical work is not directly testing this model; to the extent that it is possible, we do so in Section IV.C.

\section{II.A. Real Economy}

Log real aggregate dividends (which equal the endowment), $d_{t}=\ln D_{t}$, follow

$$
\Delta d_{t+1}=\mu_{t}+\nu_{d, t+1}
$$

The expected growth of the endowment (the drift), $\mu_{t}$, varies randomly over time, following an $\mathrm{AR}(1)$ process:

$$
\mu_{t+1}=(1-\phi) \bar{\mu}+\phi \mu_{t}+\nu_{\mu, t+1}
$$

The conditional variances of both news terms are both higher on announcement days:

$$
\operatorname{Var}_{t}\left[\nu_{x, t+1}\right]=\sigma_{x, L}^{2}+\left(\sigma_{x, H}^{2}-\sigma_{x, L}^{2}\right) A_{t+1}
$$

for $x=d, \mu$, where $A_{t+1}$ is a deterministic indicator variable that equals one if there is a pre-scheduled announcement between dates $t$ and $t+1$ and zero otherwise, and $\sigma_{x, H}>\sigma_{x, L}$. The exposition is considerably simplified if we assume that news about current and expected future endowment growth are uncorrelated.

This model is essentially that of Bansal and Yaron (2004) with the addition of deterministic changes in variances due to announcement effects, and we use a similar approximation to solve the model in closed form. Note that the announcement effects on variances are assumed and the model is used to derive the resulting announcement effects on prices and expected returns. 


\section{II.B. Preferences}

A representative investor chooses an optimal consumption path and invests in a claim to the aggregate endowment and a risk-free asset. The investor has recursive Epstein-Zin preferences

$$
U_{t}=\left((1-\beta) C_{t}^{1-\frac{1}{\psi}}+\beta\left(E_{t}\left[U_{t+1}^{1-\gamma}\right]\right)^{\frac{1-\frac{1}{\psi}}{1-\gamma}}\right)^{\frac{1}{1-\frac{1}{\psi}}},
$$

where $\beta$ is the time discount rate, $\gamma$ is the coefficient of relative risk aversion, and $\psi$ is the elasticity of intertemporal substitution (EIS). When $\gamma=1 / \psi$, these preferences nest the special case of power utility. Market clearing requires $C_{t}=D_{t}$.

We use recursive Epstein-Zin utility rather than the simpler power utility, because in our equilibrium model power utility has some empirically unattractive properties (when risk aversion is greater than one). Specifically, as noted by Bansal and Yaron (2004), increases in aggregate risk induce an increase in desired precautionary saving, which in equilibrium reduces expected returns on all assets (the wealth effect) and reduces desired portfolio weights on riskier assets (the substitution effect). Assuming investors have power utility preferences requires the wealth effect to dominate the substitution effect, implying that valuations of even risky assets should be increasing in aggregate risk (holding cash flows constant). Furthermore, under power utility, changes in expected consumption growth do not affect risk premia. The more general Epstein-Zin framework avoids these unappealing implications. ${ }^{9}$

\footnotetext{
${ }^{9}$ See Bansal, Khatacharian, and Yaron (2005) for evidence that both higher aggregate uncertainty and lower expected consumption growth decrease risky asset valuations.
} 


\section{II.C. Real Risk-free Rate}

In equilibrium, the investor consumes the aggregate endowment $D_{t}$ each period, and the risk-free asset is in zero net supply. The equilibrium log risk-free rate is then given by

$$
\begin{aligned}
r_{f t+1}= & -\ln \beta+\frac{1}{\psi}\left(\mu_{t}+\frac{1}{2} \operatorname{Var}_{t}\left[\Delta d_{t+1}\right]\right)-\gamma\left(1+\frac{1}{\psi}\right) \frac{1}{2} \operatorname{Var}_{t}\left[\Delta d_{t+1}\right] \\
& -\left(\gamma-\frac{1}{\psi}\right)\left(1-\frac{1}{\psi}\right) \operatorname{Var}_{t}\left[\frac{\rho}{1-\rho \phi} \mu_{t+1}\right]
\end{aligned}
$$

The log risk-free rate consists of four terms. The first term depends on the rate of time preference. The second depends on the log expected growth rate of consumption. This term is independent of risk aversion $\gamma$, but not of risk $\operatorname{Var}_{t}\left[\Delta d_{t+1}\right]$ because of Jensen's inequality: for risk-neutral investors, an increase in the variance of log dividend growth increases the log risk-free rate because log expected dividend growth increases, reducing desired saving.

The third term is a precautionary saving term that is zero for risk-neutral investors. For risk-averse investors, an increase in aggregate risk raises desired precautionary saving, reducing the market-clearing risk-free rate. The precautionary saving effect of increased risk dominates the effect through the second term if and only if investors are sufficiently willing to substitute consumption across time (increasing in $\psi$ ) relative to their willingness to substitute across states (decreasing in $\gamma$ ). A necessary and sufficient condition for the risk-free rate to be decreasing in aggregate risk is that $\psi \geq((1 / \gamma)-1)$. Since $\psi$ is weakly positive, this condition is always fulfilled for investors with greater than unit risk aversion.

The fourth term is an additional precautionary saving term proportional to the variance of the permanent component of shocks to expected endowment growth. This term is zero for both investors with unit elasticities of intertemporal substitution and for investors with power utility. For the case of $\gamma$ and $\psi$ greater than one, this term reduces the risk-free rate on announcement days. Risk-averse investors who are highly willing to substitute future for current consumption (those with high $\psi$ ) are most prone to changing their desired consumption plans in response to permanent changes in consumption growth. Such investors will wish 
to save more as the variance of such news increases (holding the risk-free rate constant).

The total precautionary savings effect on the risk-free rate is the sum of the third and fourth terms, and will be higher on announcement days provided $\gamma$ and $\psi$ are both greater than one. Since investors are long-lived, any such additional desired saving cannot be very large, but even long-lived investors put some weight on smoothing consumption from day to day.

\section{II.D. Stock Market Returns}

The log return on the risky claim to the aggregate endowment is

$$
\begin{aligned}
r_{M K T, t+1}= & -\ln \beta+(\gamma-1)\left(1-\frac{1}{\psi}\right) \frac{1}{2} \operatorname{Var}_{t}\left[\nu_{d, t+1}+\frac{\rho}{1-\rho \phi} \nu_{\mu, t+1}\right]+\frac{1}{\psi} \mu_{t} \\
& +\nu_{d, t+1}+\left(1-\frac{1}{\psi}\right) \frac{\rho}{1-\rho \phi} \nu_{\mu, t+1} .
\end{aligned}
$$

Expected market returns are higher on announcement days provided $(\gamma-1)(1-(1 / \psi))>$ 0 . For the leading empirical case of $\gamma>1$, this condition requires the elasticity of intertemporal substitution $\psi$ to be greater than one. ${ }^{10}$ Investors desire both to increase saving (a wealth effect) when aggregate risk increases and to substitute out of risky into risk-free assets (substitution effect). Provided that $\psi>1$, the substitution effect will dominate the wealth

effect, so that in equilibrium expected returns on risky assets will increase, while those on very low-risk assets will decrease.

\footnotetext{
${ }^{10}$ Recent work by Bansal and Yaron (2004), Bansal, Tallarini, and Yaron (2008), Vissing-Jorgenson (2002), and others presents evidence and arguments in favor of $\psi>1$.
} 
The conditional market risk premium is

(8) $\ln E_{t}\left[\frac{1+R_{M K T, t+1}}{1+R_{f, t+1}}\right]=E_{t}\left[r_{M K T, t+1}\right]-r_{f, t+1}+\frac{\operatorname{Var}_{t}\left[r_{M K T, t+1}\right]}{2}$

$$
\begin{aligned}
& =-\operatorname{Cov}_{t}\left[m_{t+1}, r_{M K T, t+1}\right] \\
& =\gamma \operatorname{Var}_{t}\left[\Delta d_{t+1}\right]+\left(\gamma-\frac{1}{\psi}\right)\left(1-\frac{1}{\psi}\right) \operatorname{Var}_{t}\left[\frac{\rho}{1-\rho \phi} \mu_{t+1}\right] \\
& =\gamma \operatorname{Var}_{t}\left[r_{M K T, t+1}\right]+\frac{\gamma-1}{\psi} \operatorname{Cov}_{t}\left[r_{M K T, t+1}, \frac{\rho}{1-\rho \phi} \mu_{t+1}\right] .
\end{aligned}
$$

It will be higher on announcement days provided $\psi$ is not too low. For the special cases of power utility or unit intertemporal elasticity of substitution, the variance of the permanent component of shocks to economic growth (the second term) does not affect consumption. When both $\gamma$ and $\psi$ are greater than one, the market risk premium is increasing in the variance of this permanent component. Thus, market risk premia can be considerably higher on announcement days if investors expect to receive more news about future economic growth on such days.

In this model, the market risk premium is not necessarily proportional to its conditional return variance. Since the stock market return exhibits a positive covariance with permanent shocks to expected economic growth, conservative investors (those with $\gamma>1$ ) will demand higher risk premia on announcement days even if the increase in market variance is small. Such investors require compensation for the tendency of the market to perform poorly when news about future economic growth is bad. In consequence, Sharpe ratios can be much higher on announcement days.

\section{II.E. Nominal Bonds and Inflation}

In order to model announcement effect on bonds, we next introduce inflation shocks. The log dollar price of an $\mathrm{N}$-period nominal discount bond is $p_{n, t}^{\$}$ and its real holding period return is

$$
r_{n, t+1}=p_{n-1, t+1}^{\$}-p_{n, t}^{\$}-\pi_{t+1}
$$


where $\pi$ is the log rate of inflation. We assume

$$
\pi_{t+1}=z_{t}+\eta_{\pi, t+1}
$$

and expected inflation $z_{t}$ follows

$$
z_{t+1}=(1-\lambda) \bar{\pi}+\lambda z_{t}+\eta_{z, t+1}
$$

Once again, the conditional variances of realized inflation and expected inflation shocks are higher on announcement days. The structural source of inflation and its relation to real variables is beyond the scope of this paper. However, we assume that neither shocks to realized or expected inflation are correlated with shocks to realized endowment growth $\nu_{d, t+1}$. The signs of the correlations between expected inflation and expected real endowment growth and between realized inflation and expected endowment growth are discussed below. Following Campbell and Viceira (2002), chapter 3, it is helpful to write out the dependencies of the inflation shocks on each other and on shocks to the drift:

$$
\eta_{z, t+1}=\beta_{z \mu} v_{\mu, t+1}+\varepsilon_{z, t+1}
$$

and

$$
\eta_{\pi, t+1}=\beta_{\pi \mu} v_{\mu, t+1}+\beta_{\pi z} \varepsilon_{z, t+1}+\varepsilon_{\pi, t+1}
$$

The shocks $v_{\mu, t+1}, \varepsilon_{z, t+1}$, and $\varepsilon_{\pi, t+1}$ are orthogonal but have higher variances on announcement days. The loadings $\left(\beta_{z \mu}, \beta_{\pi \mu}\right.$, and $\left.\beta_{\pi z}\right)$ are assumed to be the same on all days for simplicity. In order to generate a positive inflation risk premium, we require that $\beta_{z \mu}$ be negative, so that shocks to expected inflation are negatively related to shocks to expected economic growth. 


\section{II.F. Nominal Bond Risk Premia}

In real terms, consistent with the rest of this section, risk premia on nominal bonds are given by

$$
\begin{aligned}
& E_{t}\left[r_{n, t+1}\right]-r_{f, t+1}+\frac{1}{2} \operatorname{Var}_{t}\left[r_{n, t+1}\right]=\operatorname{Cov}_{t}\left[-m_{t+1}, p_{t+1}^{\$ n-1}-p_{t}^{\$ n}-\pi_{t+1}\right] \\
= & \left(\gamma-\frac{1}{\psi}\right) \frac{\rho}{1-\rho \phi} \operatorname{Var}_{t}\left[\mu_{t+1}\right]\left(-\frac{1}{\psi} \frac{1-\phi^{n-1}}{1-\phi}-\frac{1-\lambda^{n-1}}{1-\lambda} \beta_{z \mu}-\beta_{\pi \mu}\right) .
\end{aligned}
$$

The risk premia depend on three terms. The first term is the risk premium on an N-period real bond. When either $\gamma$ and $\psi$ are both greater or both less than one, this implies that risk premia are lower on announcement days by an amount increasing in magnitude with bond maturity. Since the short-term real interest rate depends positively on expected endowment growth, and real long-term bond holding period returns are negatively correlated with the short-term real rate, long-term real bonds offer desirable hedges against the risk of a decline in expected economic growth. As this risk is higher on announcement days, longer-term real bonds should underperform by more on such days.

The second term depends negatively on the covariance between shocks to expected inflation and shocks to expected real endowment growth. In order to generate a positive inflation risk premium, this covariance must be negative. Although there is evidence that the inflation risk premium may have declined over time, most studies agree that it has always been positive (see, for example, Buraschi and Jiltsov (2007) and Campbell, Sunderam, and Viceira $(2009))$.

Finally, the third term depends negatively on the covariance between shocks to realized and expected inflation and expected economic growth. The sign of this covariance is a matter of debate, but it is likely to be small in magnitude and is the same for all maturities.

The risk premium on two nominal bonds with maturities $n+1$ and $n$ is increasing in 
maturity, and higher on announcement days, provided

$$
-\beta_{z \mu}>\frac{1}{\psi}\left(\frac{\phi}{\lambda}\right)^{n-1}
$$

For sufficiently short-term bonds the risk premium can decline with maturity and will be lower on announcement days. The model therefore predicts that for short-term bonds the average excess returns on announcement days can be lower than on non-announcement days, but should always be higher for longer-term bonds.

\section{Evidence on Announcement Day Returns}

\section{III.A. Pre-scheduled Macroeconomic Announcements}

We obtain dates of pre-scheduled monthly macroeconomic news announcements from the Bureau of Labor Statistics from 1958 to 2009 and from the Federal Reserve from 1978 to 2009. We have 157 pre-scheduled CPI announcements from January 1958 to January 1971 and 467 for the PPI from February 1971 to December 2009. We drop the CPI after PPI announcements become available in February 1971, since PPI numbers for a given month are always released a few days earlier, thereby diminishing the news content of CPI numbers. ${ }^{11}$ We have 621 employment announcements from January 1958 to December 2009. FOMC interest rate announcements start in January 1978 and end in December 2009. Before February 1994, we assume the FOMC decision became public one day after its meeting (as in Kuttner (2001)). We exclude any unscheduled announcements, leaving us with 279 FOMC observations. 51 of the announcement days in our sample had more than one announcement, while a further 23 were non-trading days. The remaining sample contains 1,450 announcement days versus 11,641 non-announcement days. Interestingly, only 29 of the pre-scheduled announcements in our sample occurred on a Monday, representing about $2 \%$ of overall announcements. In the second half of our sample, there is only one Monday announcement.

Our choice of announcement types is primarily dictated by the availability of data. CPI is

\footnotetext{
${ }^{11}$ Our results are robust to the inclusion of CPI announcements after January 1971.
} 
the first macroeconomic variable for which the Bureau of Labor Statistics issued regular news releases (according to data available on its website), followed four years later by employment. We need a long sample for our analysis to ensure the average surprise is close to zero, so that announcement day returns do not reflect a period of particularly good or bad news. ${ }^{12}$ Moreover, both employment and inflation clearly constitute important macroeconomic news, as do FOMC announcements. ${ }^{13}$

Our measure of stock market return is the daily return on the Center for Research in Security Prices (CRSP) value-weighted NYSE/Nasdaq/Amex all share index, including dividends. To calculate excess returns, we infer a daily risk-free rate from the monthly risk-free rate (obtained from Kenneth French's website), assuming it to be constant over the month. This biases downwards our estimate of the difference in average excess returns between announcement and non-announcement days, since we also find evidence consistent with a lower daily risk-free rate on announcement days.

We obtain daily Treasury bill (T-bill) returns from the CRSP daily Treasuries file starting in June 1961 (the first date available) and ending in December 2009. Our proxy for the overnight risk-free rate is the daily return on the T-bill in the CRSP file with maturity closest to 30 days. ${ }^{14}$ Our results do not depend on the exact choice of the number of days until maturity.

For Treasury securities with longer maturities, we use returns provided by CRSP's Daily Treasury Fixed Term Indexes File. These returns are meant to reflect the performance of a hypothetical Treasury bond with fixed maturity, and are calculated using a procedure similar to the one we employ for calculating our daily risk-free rate.

We obtain constant-maturity 30-day implied volatility from the CBOE S\&P 100 Vix

\footnotetext{
${ }^{12} \mathrm{~A}$ long sample should also address potential critiques based on the peso problem hypothesis.

${ }^{13}$ See Jones, Lamont, and Lumsdaine (1998), Bernanke and Kuttner (2005), and Boyd, Hu, and Jagannathan (2005) for further evidence of the variables' relevance.

${ }^{14}$ The CRSP file contains very few observations for bonds with initial maturities of less than 6 months. As a result, hardly any of the bills in our sample are on-the-run 30-day T-bills.
} 
index, available daily beginning in 1986. These volatilities are then squared to convert them into variances, and the daily difference from market close to market close is calculated. Estimates of the change in stock market risk based on prices at a point in time such as implied volatilities could be more accurate than estimates based on realized volatility.

\section{III.B. Stock Market Excess Returns}

Table 1 presents our main result: the average excess return on the stock market is 11.4 bps on announcement days versus 1.1 bps on other days. The difference between the returns on the two kinds of days averages 10.3 bps and a $t$-test for a difference in means (allowing for different variances) gives a $t$-statistic of 3.77. The non-announcement day returns are not only much lower but are actually not even statistically significant $(t$-statistic $=1.29)$. Excluding outliers (observations outside the 1st and 99th percentiles of each sample), the average excess returns are 11.7 and $1.3 \mathrm{bps}$, respectively, with a $t$-statistic for different means of 4.55, and the non-announcement day returns are only marginally significant ( $t$-statistic $=$ 1.88). This evidence suggests that macroeconomic risks represent important priced factors for stock returns, as the observed equity risk premium is much higher on announcement days.

\section{[TABLE 1 ABOUT HERE]}

Our hypothesis is that announcement days are fundamentally riskier than other days. The standard deviation of announcement day returns is 98.6 bps versus 94.6 bps for other days (81.8 versus 75.4 when excluding outliers), and we can reject the hypothesis of equal variances at the $5 \%$ significance level. However, the dispersion of announcement day returns is only $4-6 \%$ higher, so that the Sharpe ratio is about ten times higher compared to nonannouncement days. Furthermore, announcement day returns exhibit equal skewness as those on other days, and the distribution of announcement day returns has a thinner left tail than the non-announcement day distribution. ${ }^{15}$ It appears that announcement days are not riskier simply because the distribution of announcement day returns is less attractive

\footnotetext{
${ }^{15}$ This remains true even if we exclude the October 1987 market crash, although there is obviously no good reason to exclude such events when evaluating tail risk.
} 
to a myopic investor. Consequently, if announcement day risk premia are higher because of higher fundamental risk, this must be because of higher exposure to state variable risk on announcement days. ${ }^{16}$

Table 2 shows evidence from regressions of returns on an announcement day dummy together with controls. The regression coefficients are estimated using ordinary least squares (OLS), and $t$-statistics are computed using Newey-West standard errors (with 5 lags, but our results do not change with different specifications). ${ }^{17}$ Panel A is for the full sample of 13,091 days and Panel B excludes outliers using the same cut-offs as above. The first column of each panel reproduces the difference-in-means result of Table 1: the announcement day dummy has a significantly positive coefficient. We then control for market return lagged one day and squared lagged market return. The coefficient on the lagged market return is positive and significant, in accordance with previous work. Finally, we include day of the week dummies for Monday through Thursday. The presence of these dummies should absorb any impact on returns by different days of the week, which may stem from payment lags, higher or lower trading activity on particular days, or behavioral biases. We confirm that returns are significantly lower on Mondays (even excluding outliers) and otherwise find no significant day-of-the-week effects. The announcement day effect remains positive and highly significant in all specifications, although slightly lower once day-of-the-week effects are included.

\section{[TABLE 2 ABOUT HERE]}

\footnotetext{
${ }^{16}$ Pollet and Wilson (2010) show that, when the stock market is a poor proxy for the portfolio of aggregate wealth, changes in the average correlation between stock returns can nevertheless reveal changes in aggregate risk. We use estimates of daily average correlation based on intraday returns starting in 1995, and find that the mean announcement day correlation equals 0.245 versus 0.216 on other days (with a $t$-statistic for the difference of 3.78). This result suggests, as do our findings on realized and implied volatility, that aggregate risk is higher on announcement days, but that the increase is not of the same order of magnitude as the increase in risk premia.

${ }^{17}$ Our findings remain unaltered if we instead jointly estimate announcement day effects on both the mean and conditional volatility (using a $\operatorname{GARCH}(1,1)$ model similar to the one used in Jones, Lamont, and Lumsdaine (1998)). These results are available on request.
} 
We do not include the contemporaneous announcement surprise in our controls. We take this approach for two reasons. First, because the correlation between the true announcement surprise and the announcement day dummy (which is deterministic) is zero by definition, its exclusion does not bias our estimates of the announcement day effect (whereas the inclusion of a poorly estimated surprise may bias them). Second, the magnitude and even the sign of the response coefficient to the surprise may well vary over time, which complicates any analysis relying on these coefficients. For example, Boyd, Hu, and Jagannathan (2005) show that unemployment shocks have opposite impact on stock returns in expansions and recessions. In our robustness tests, we show that controls for announcement surprises have no effect on our findings.

\section{III.C. Risk-free Rate}

Table 3 presents findings on the distributions of announcement day and non-announcement day returns on 30-day T-bills. Our sample starts slightly later (1961, rather than 1958), but is otherwise identical to the stock market sample of announcements.

\section{[TABLE 3 ABOUT HERE]}

Panel A shows that the average announcement day return for 30-day T-bills is $1.5 \mathrm{bps}$ versus 2.3 bps for non-announcement days. The difference of 0.7 bps is statistically significant with a t-statistic of 14.49 , and is also economically significant relative to the sample mean of 2.2 bps. The respective standard deviations are 1.6 and 2.5 bps. 30-day T-bill returns are actually less volatile on announcement days, but the main point is that both of these volatilities are extremely small, as one would expect if these returns represented good proxies for the risk-free rate. The distribution of announcement day returns on 30-day T-bills is everywhere below that of non-announcement day returns.

The statistical significance of the result that 30-day T-bill returns are lower on announcement days is stronger if outliers are excluded, with the $t$-statistic for the difference increasing to 21.4. The exclusion of outliers is more important in this case because of the greater pos- 
sibility of data error, resulting from the fact that the prices of bond trades are not reported to an exchange.

Table 4 gives our regression results. As before, column 1 of Panel A reproduces the difference-in-means result. Column 2 controls for lagged return and lagged squared return. Not surprisingly, T-bill returns are highly autocorrelated, but the announcement day effect is still highly significant. Column 3 controls for day-of-the-week effects. Returns on T-bills appear to depend strongly on the day of the week, but, even with the inclusion of dummies for different days, the announcement day effect is still very significant (although substantially smaller). We conclude that the evidence is consistent with increased announcement day risk reducing the risk-free rate.

\section{[TABLE 4 ABOUT HERE]}

Our regression shows that T-bill returns are extraordinarily high on Mondays. One potential explanation for this is the existence of a weekend effect for T-bills: three days pass between the Friday T-bill price observation and the Monday observation, whereas only one day passes between all other consecutive price observations (excluding holidays).

In unreported tests, we raise the gross Monday return for T-bills and Treasury bonds to the power of one third and repeat our analysis. (This adjustment is not necessary in the case of stock market returns, as in their case the random component dominates the deterministic component due to the passing of time.) Since Monday is almost never an announcement day, this procedure distinguishes between an announcement day effect on daily T-bill and bond returns and a mere weekend effect. Crucially, all our findings continue to hold with this adjustment.

\section{III.D. Treasury Bond Excess Returns}

In contrast to T-bills, government securities with longer maturities represent risky assets at a daily horizon. If held to maturity, long-term Treasury bonds will provide a guaranteed (nominal) rate of return, but in the meantime their daily price changes will not be fully 
predictable and will reflect factors such as changes in interest rates. The possibility of such changes can result in longer-term bonds displaying greater differences between announcement and non-announcement day returns. ${ }^{18}$

Our model predicts that at long maturities government bonds should have higher excess returns on announcement days and that the difference should be increasing with maturity, provided that inflation risk premia are positive and shocks to expected inflation are more persistent than shocks to expected economic growth. At the short end of the term structure, it is possible for real interest rate risk premia to dominate inflation risk premia, and thus short-term bond average excess returns can be lower on announcement days (see equation (16)).

This hypothesis is confirmed by the data. Figure 1 shows how the difference between announcement and non-announcement day excess returns varies with a bond's maturity. As predicted, the performance differential uniformly increases as we increase a bond's time-tomaturity. For a 1-year bond, the average announcement day excess return is actually 0.5 bps lower than the average on other days, with a $t$-statistic of 2.22. This suggests 1-year bonds are relatively riskless assets (at a daily horizon). However, as we increase a bond's maturity, its announcement day returns become higher than non-announcement day returns. For 5-year bonds, the return differential is $2.6 \mathrm{bps}(t$-statistic $=2.57)$, and it then grows to 3.4 bps $(t$-statistic $=2.23), 4.1$ bps $(t$-statistic $=2.04)$, and 4.5 bps $(t$-statistic $=2.02)$ for 10-, 20-, and 30-year bonds respectively. These findings for longer-dated Treasury securities are similar to those reported in Jones, Lamont, and Lumsdaine (1998) for the 1979-1995 period, and are consistent with the hypothesis that investors expect higher returns on riskier assets on days when macroeconomic news is scheduled to be released.

\section{[FIGURE 1 ABOUT HERE]}

\footnotetext{
${ }^{18}$ E.g., simple up or down shifts in the yield curve will have the greatest impact on the Treasury bonds with the longest maturities.
} 


\section{III.E. Can the Same Parameters Account for All Announcement Effects?}

Our model proposes a unified explanation for announcement effects on the risk-free rate, the equity risk premium, and bond risk premia. Having presented our main results, it is now appropriate to ask whether the model provides a quantitatively as well as qualitatively satisfactory explanation. To address this issue, we show and discuss the results of a simple calibration exercise.

Given that equation (6) requires $\gamma$ and $\psi$ to both be greater than one for the risk-free rate effect to exist, we choose other parameters for the model that can match our estimates for the stock market. Specifically, for $\gamma=1.2$ and $\psi=1.001$, we can choose other parameters to match the announcement and non-announcement day market average excess returns and volatilities of returns perfectly. ${ }^{19}$ For example, setting $\phi=0.836, \sigma_{d}^{A}=15.4 \%, \sigma_{d}^{N}=15.0 \%$, $\sigma_{\mu}^{A}=4.4 \%$, and $\sigma_{\mu}^{N}=8 \times 10^{-11 \%}$, all quoted on an annualized basis and assuming 250 trading days per annum, generates the required moments.

Are these numbers also consistent with observed bond and T-bill returns? For bond risk premia, we find that we can generate all the observed announcement and non-announcement day average excess returns almost perfectly (with a root mean squared error of $0.25 \mathrm{bps}$ ) if we assume $\lambda=0.833$ (annualized), $\beta_{z \mu}=-1.07$, and $\beta_{\pi \mu}=0$. Actual (implied) bond average excess returns (expressed in bps) are then: 0.0 (0.1) for 1-year notes; 3.1 (2.8) for 5-year notes; 3.6 (4.0) for 10-year bonds; 4.3 (4.3) for 20-year bonds; and 4.5 (4.5) for 30-year bonds. For non-announcement day average excess returns, all are predicted by the model to be zero, which is quite close to the actual estimates of $0.4,0.5,0.2,0.4$, and 0.1 respectively. We conclude that the same parameters of the model can match both stock market and bond risk premia (given stock market variance) on both announcement and non-announcement days for bond maturities of one year and above.

With these parameters, the implied difference between the average risk-free rate on an-

\footnotetext{
${ }^{19}$ The value of $\gamma$ cannot be too high as a lower bound for $\sigma_{\mu}^{N}$ is zero. At that point, equation (8) sets $\gamma$ equal to the price of market risk on non-announcement days, which we estimate to be very low. Given a low $\gamma$, and very similar market variances on both types of day, equation (7) then requires $\psi$ to be close to one.
} 
nouncement days and non-announcement days is $-10.2 \mathrm{bps}$, as opposed to an actual reduction of -0.7 bps. The model implied reduction is thus nearly fifteen times too large in magnitude. Inspection of equation (6) shows that the announcement day effect on the risk-free rate contains a term that is equal and opposite to the effect on the stock market risk premium, and that the other terms are likely to be small, given the small observed difference in market return volatility. Since the risk premium increases by over 10 bps on announcement days, the model-implied effect on the risk-free rate is counterfactually large at around -10 bps.

Why might the actual effect on the risk-free rate be far smaller than the one implied by our model? One possible explanation is that ours is a representative agent endowment model in which bonds and bills are assumed to be in zero net supply. When the agent wishes to reduce his holdings of risky assets, there is no other agent to accommodate him, so the risk-free rate must fall to offset his increased demand. In reality, cash, bills and other close substitutes may be much more elastically supplied (relative to equities and long-term bonds), thereby reducing the impact of announcement risk on the risk-free rate relative to the impact on equities or bonds.

\section{III.F. Announcement Surprises}

A possible alternative explanation for our central results is that announcement returns have a high realized Sharpe ratio in our sample because 1958-2009 has been a period of unusually benign economic conditions for the U.S., and investors mainly learned this on announcement days. We now evaluate this idea. We note, however, that this explanation implicitly concedes that announcement days are riskier, since these are the days when investors learn the state of the economy. Furthermore, the announcement effect on market returns is present in all but one consecutive 5-year subperiod in our sample, so that investors would have had to be surprised on the upside not just over the entire 1958-2009 period but also in each 5-year subperiod except one.

A straightforward test of this "good-news hypothesis" is to run the following regression 
for our test assets:

$$
R_{t}=\beta_{0}+\beta S_{t}+\theta A_{t}+\text { Controls }_{t}+\varepsilon_{t},
$$

where $R$ is the asset return, $S$ is the unexpected component of an economic announcement, $A$ is an announcement day dummy, and Controls is a set of controls. If the sample average $S$ is positive, then omitting $S$ might bias upwards our estimate of the announcement effect $\theta$.

Any estimate of the announcement surprises $\widehat{S}_{t}$ from a regression with a non-zero intercept will have a zero in-sample mean. Therefore, we must use pseudo out-of-sample forecast errors for announced inflation and unemployment when estimating regressions. For interest rate announcements, we use federal fund futures, as in Bernanke and Kuttner (2005), and the surprise is then just the difference between the FOMC decision and the futures price-implied interest rate prediction.

To forecast unemployment, we use the model in Boyd, Hu, and Jagannathan (2005) (BHJ), equation (1):

$$
\begin{aligned}
\text { Unem }_{t}-\text { Unem }_{t-1}= & b_{0}+b_{t} I P_{t-1}+b_{2} I P_{t-2}+b_{3} I P_{t-4} \\
& +b_{4}\left(\text { Unem }_{t-1}-U n e m_{t-2}\right)+b_{5} T B 3_{t}+b_{6} B A_{t}+\varepsilon_{t},
\end{aligned}
$$

where Unem is the unemployment rate, IP is the growth rate of monthly industrial production, $T B 3$ is the change in the 3 -month T-bill rate, and $B A$ is the change in the default yield spread between Baa and Aaa corporate bonds (all monthly). We get Unem and IP from the Bureau of Labor Statistics, and TB3 and BA from Global Financial Data. We compute forecasts using rolling regressions starting in 1953 (so that the forecast in period $t$ is calculated using coefficients estimated with data from 1953 to period $t-1$ ).

To forecast inflation, we use an IMA(1,1) model, as in Nelson and Schwert (1977) (with monthly data) and Stock and Watson (2007) (with quarterly data). Stock and Watson (2007) 
present evidence that this forecast performs as well as any other over our sample period. The moving average coefficient is estimated using a ten-year rolling window of past observations.

Since BHJ show that the impact of economic news may vary depending on the business cycle, we also include specifications in which we interact surprises with expansion and recession indicators. ${ }^{20}$ As an additional check, we repeat our analysis using median forecasts from the Society of Professional Forecasters (SPF), available from the Federal Reserve Bank of Philadelphia and starting in the third quarter of 1981 (for inflation). These are only reported quarterly, so we use the same SPF forecast for each month in a given quarter.

Table 5 reports the results for the stock market (Panel A) and the risk-free rate (Panel B) as dependent variables. In summary, our estimates of the announcement effect on both expected market returns and risk-free rates are unaffected when we include announcement surprises as controls. The announcement dummy coefficient in the stock market return regression is 8.1 (7.6 with no business cycle indicators) when we use forecasts from equation (18) and 11.3 (9.6 with no business cycle indicators) when we use SPF forecasts (with the sample starting in 1982 in the latter case). These coefficients are strongly statistically significant and quite close in magnitudes to the estimates with no announcement surprise controls.

\section{[TABLE 5 ABOUT HERE]}

In the T-bill regressions, the coefficients on the announcement dummies are -0.15 using both model-based and SPF forecasts. Again, they are all highly significant and very similar to the ones calculated when announcement surprise controls are omitted. The only surprises with significant impact on T-bill returns are FOMC ones, which is exactly what we should expect (it would be quite worrying if T-bill prices did not respond to federal funds rate changes).

Perhaps surprisingly, no announcement surprises have a statistically significant impact on stock market returns in any of our specifications. At first glance, this seems to conflict

\footnotetext{
${ }^{20}$ For example, if negative unemployment surprises represent good news in recessions and bad news in booms, the average news might have been good in our sample even if the average surprise equaled zero.
} 
with the results in BHJ (for unemployment) and Bernanke and Kuttner (2005) (for FOMC decisions). However, when we restrict our sample to the same period as the one in BHJ (1972-2000), we get results that are similar in magnitudes and statistical significance. We can also replicate the results in Bernanke and Kuttner (2005) when we add unscheduled FOMC announcements to our sample. It seems that their findings are driven exclusively by interest rate changes that occurred outside of the regular FOMC meeting schedule.

In unreported tests, we find that our results for Treasury bonds also hold when we add announcement surprises as controls. Taken together with our finding that stock market announcement effects exist in all but one 5-year subperiod in our sample, we conclude that it is unlikely that our results can be explained by good average announcement news during the 1958-2009 period.

\section{III.G. Subsamples and Other Robustness Tests}

Our findings hold separately in each half of the sample, with the difference between announcement and non-announcement day stock market returns (8.7 bps in the 1958-1983 period vs. 11.4 bps in the 1984-2009 period) and risk-free rates (-0.7 and -0.6 bps) almost the same across the two subsamples. This further strengthens the case that the announcement day premium is not a temporary phenomenon or a chance occurrence. The results are also present for each type of announcement. When we divide the sample further into consecutive 5-year periods, the stock market excess return is higher on announcement days in 9 out of 10 periods, and the T-bill returns are lower in 9 out of 10 periods.

The announcement day returns are higher for all 10 Fama-French industry portfolios, with the difference being statistically significant for every industry except for Durables and Telephone and Television Transmission. Finally, various calendar anomalies, such as the January

effect, the turn-of-the-month effect (high equity returns over a four-day interval beginning with the last trading day of the month, first discovered by Ariel (1987) and Lakonishok and Smidt (1988)), the first-half-of-the-month effect (positive stock returns only during the 
first half of calendar months, as in Ariel (1987)), the holiday effect (good stock market performance ahead of market holidays, documented by Ariel (1990)), or seasonality in returns induced by payment lags (Flannery and Protopapadakis (1988)), do not explain any of our results. ${ }^{21,22}$

\section{Additional Tests and Other Supporting Evidence}

In this section we show additional results on announcement day effects. ${ }^{23}$ We present evidence that the announcement day excess return increases with conditional stock market variance, while there is no corresponding effect for non-announcement days (i.e., at times of high uncertainty, the announcement day risk premium is higher); that stock market implied variance is higher immediately before announcements; that announcement day returns predict consumption growth better than non-announcement day returns, though only in the second half of our sample; and that the stock market betas of government bonds are much higher on announcement days and the difference in betas is increasing with maturity.

\section{IV.A. Conditional Variance and Stock Market Excess Returns}

Our basic argument is that investors demand compensation for the higher risk of learning bad news about the state of the economy on announcement days, resulting in a higher expected return on these days. In times of high uncertainty, the risk of learning bad news is higher than in normal times. Consequently, the differential between returns on announcement and non-announcement days should be greater during such periods. It is interesting to note that announcement day returns were on average particularly high during the crisis period in 2008 and 2009, even though some of the worst announcement day returns in our sample occurred then.

\footnotetext{
${ }^{21}$ We control for these effects by introducing dummies for each calendar month, a dummy for the four trading days around the turn of the month, a dummy for the first half of a month, dummies for trading days just before and just after a holiday, and holiday dummies interacted with day-of-the-week dummies.

${ }^{22}$ All these results are available on request.

${ }^{23}$ All of these findings are implied by our model, but we do not formally derive every prediction.
} 
In more formal terms, the higher Sharpe ratio of announcement day stock market returns indicates that most of the difference between announcement and non-announcement returns is due to higher state variable risk and not to higher market variance. It is then simple to show that this difference is increasing in the conditional variance of the market return. ${ }^{24}$

To test this hypothesis, we run the same regression specification as in Table 2 but add as dependent variables the lagged realized variance of stock returns and its interaction with the announcement day dummy. We use the realized variance (over the last 100 trading days) as a proxy for the conditional variance, as in Campbell, Lettau, Malkiel, and Xu (2001). The coefficient on the interaction term (using demeaned variance) is significantly positive with a $t$-statistic of 2.22. By contrast, the variance coefficient on its own is negative and not statistically significant. The point estimates imply that a doubling of stock market variance from its sample mean increases the announcement day risk premium by 6.0 bps (relative to the sample mean of $11.4 \mathrm{bps}$ ), while not affecting (or even reducing if we use the insignificant coefficient on the realized variance) the non-announcement day risk premium. ${ }^{25}$ This evidence is consistent with our model, and further supports the hypothesis that announcement days are fundamentally riskier.

\section{IV.B. Implied Variance}

Our model predicts a drop in Vix, or other Black-Scholes implied volatility measures, from before to after announcements. Intuitively, one can think of 30-day ahead Vix as a "portfolio" of 1-day conditional volatilities. When a high-volatility day, such as an announcement day, drops out and is replaced by a low-volatility one, the "portfolio" volatility drops. We present results on squared implied volatility (implied variance) as these are slightly easier to interpret.

Panel A of Table 6 gives summary statistics for the percentage change in implied variance

\footnotetext{
${ }^{24}$ See Appendix, equation (A-19).

${ }^{25}$ The mean announcement day variance is $9586 \mathrm{bps}^{2}$. The interaction coefficient is 0.00077 and the variance coefficient is -0.00014 . A doubling of variance then increases the expected excess return by $9586 *$ $0.00077-9586 * 0.00014$.
} 
from previous day market close to following day market close, and compares the changes on announcement days to those on non-announcement days. The average announcement day change is $-1.5 \%$ whereas for other days the average change is an increase of $1.4 \%$. Both estimates are statistically significant and the difference is large and highly statistically significant $(t$-statistic $=4.30)$. The median change in implied variance around non-announcement days is effectively zero. The median change around announcement days is $-2.9 \%$, and the distribution of announcement day changes lies everywhere below the distribution of nonannouncement day changes. When we exclude outliers in Panel B, our findings remain the same and become even more significant.

\section{[TABLE 6 ABOUT HERE]}

In untabulated results, we also run a regression of implied variance on an announcement dummy with controls for lagged changes in implied variance, the square of such lagged changes, and day of the week dummies. None of the results in Table 6 are materially affected. In sum, our evidence strongly suggests that the implied variance falls after macroeconomic news is released. Ederington and Lee (1996) obtain a similar result for interest rate options, while Dubinsky and Johannes (2005) document a decline in implied volatility for individual stock options after earnings announcements. ${ }^{26}$

\section{IV.C. Covariance with Consumption Growth}

Our explanation for the much higher Sharpe ratio of announcement day stock returns is that investors face higher state variable risk on these days. In our model, this state variable risk is equated to the risk of learning that future economic growth, and therefore consumption growth, will be lower than expected. A literal test of our model would then check whether

\footnotetext{
${ }^{26}$ Beber and Brandt (2009) use prices of economic derivatives to measure macroeconomic uncertainty, and show that implied volatilities of stock and bond options decline more after news releases when uncertainty is high. Li and Engle (1998) and French, Leftwich, and Uhrig (1989) show a reduction in return volatility immediately prior to a pre-scheduled announcement for the bond and the agricultural futures markets, respectively.
} 
stock market announcement day returns predict future consumption growth better than nonannouncement day returns.

Table 7 shows the results of this test. Our measure of consumption is the log real per capita consumption based on NIPA consumption data, taken from Martin Lettau's website and available at a quarterly frequency. We include three lags of consumption growth as controls (we find that only the first three are significant). We sum all the announcement day excess returns in a given quarter $t$ to obtain cumulative announcement day returns and do

the same for non-announcement day excess returns. Their sum, $r_{q, t}^{A}+r_{q, t}^{N}$, is the cumulative market excess return in quarter $t$.

The first three columns show the results of regressing quarterly consumption growth in quarter $t$ on quarter $t-1$ cumulative announcement and non-announcement returns for the full sample (consumption data end in the third quarter of 2009), the first half of the sample (1958 Q1 to 1983 Q4), and the second half (1984 Q1 to 2009 Q3). In the full sample, both types of return forecast future consumption growth. The coefficient on announcement day returns is $0.018(t$-statistic $=2.34)$ versus 0.010 for non-announcement day returns $(t$-statistic $=2.84)$. In the first half, only non-announcement day returns are significant $(t$-statistic $=$ 2.97), while in the second half only announcement day returns are significant $(t$-statistic $=$ $2.75)$.

\section{[TABLE 7 ABOUT HERE]}

The next three columns run the same regressions but replace the levels of returns with the difference between cumulative announcement and non-announcement day returns, $r_{q, t}^{A}-r_{q, t}^{N}$, and their sum, the cumulative market return. If the coefficient on the difference is positive, we can then reject the null that announcement day returns predict future consumption growth equally or less well than non-announcement day returns. The coefficient on the difference is not significant in either the full sample or in the first half. However, in the second half announcement day returns predict future consumption growth significantly better than returns on non-announcement days, with a coefficient on $r_{q, t}^{A}-r_{q, t}^{N}$ equaling 0.008 ( $t$-statistic 
$=2.39$ ). This finding is consistent with investors facing a higher risk of learning bad news about future consumption on announcement days. It is important to emphasize here that in a typical quarter there are 55 non-announcement days and only eight announcement days, but cumulative announcement day returns still offer more information about next quarter's consumption growth despite this preponderance of non-announcement days.

Why does our prediction about consumption growth only hold in the second half? An indepth investigation of this question is beyond the scope of the current paper, but we suggest three possible explanations, all of which are also consistent with the finding that $\mathrm{R}^{2}$ is almost twice as high in the second half. First, consumption data may be of poorer quality in the earlier period. Wilcox (1992) shows that NIPA data are likely to contain significant sources of error. Second, the stock market participation rate has increased over time and is much higher in the second half than the first half (see, for example, Bertaut and Starr-McCluer (2000) and Hong, Kubik, and Stein (2004)). As argued by Mankiw and Zeldes (1991) and Parker (2001), it is only stockholder consumption that should covary with stock market returns. Third, inflation was more volatile in the early half of our sample, and investors may have overestimated real consumption growth as a result of underestimating inflation in that period. Campbell and Vuolteenaho (2004) argue that inflation illusion is a significant source of potential stock mispricing, and in particular that stock market participants appear to underestimate future real dividend growth when inflation is high, as hypothesized by Modigliani and Cohn (1979). ${ }^{27}$

\footnotetext{
${ }^{27}$ Consistent with this explanation, we find that in the first half of our sample, in a similar test but replacing real with nominal consumption growth, cumulative announcement day returns predict nominal consumption growth better than non-announcement day returns (with a marginally significant t-statistic of 1.63). In the second half, only real consumption growth is better predicted by announcement day returns. These results are available from the authors on request.
} 


\section{IV.D. Bond Betas}

Table 8 shows betas of government bonds with respect to the stock market return. We regress the excess return of Treasury bonds with different maturities on the stock market excess return, the announcement day dummy, and the interaction term between the two. The coefficient on the announcement day dummy corresponds to the chart in Figure 1: it is negative for the shortest horizon $(t$-statistic $=-2.71)$ and then becomes positive for a 5 -year horizon $(t$-statistic $=2.41)$ and continues increasing monotonically with bond maturity. While 1-year bonds underperform on announcement days, those with longer maturities outperform, and this outperformance increases as maturity goes up.

We observe a similar pattern for bond betas. The interaction term, which measures the difference between bond betas on announcement and non-announcement days, is always positive and significant, and it increases with the maturity of the bond. The difference is $0.010(t$-statistic $=4.26)$ for 1-year bonds, and it then monotonically rises to $0.112(t$-statistic $=5.79$ ) for 30-year bonds. With the exception of those with a 20-year maturity, Treasury bonds do not move together with the stock market on non-announcement days. In contrast, on announcement days this comovement is always significantly positive.

\section{[TABLE 8 ABOUT HERE]}

This evidence is consistent with the existence of a priced common factor to stock and bond returns on announcement days that is less present at other times. It is also predicted by our model if the announcement day increase in the variance of news about expected future consumption growth is greater than the announcement day increase in the variance of news about current growth. In other words, provided the information that arrives specifically on announcement days is more relevant to state variables such as expected economic growth or expected inflation, as opposed to realized economic growth or realized inflation, bonds and stocks should comove more around announcements.

This point is perhaps most easily understood by considering an extreme but empirically plausible case. Suppose: (1) the only sources of time-variation in expected returns are 
expected economic growth and expected inflation; (2) investors learn nothing about current growth through announcements and nothing about expected future growth or inflation (and, by implication, interest rates) other than through announcements; (3) shocks to expected inflation are negatively correlated with shocks to expected economic growth; and (4) shocks to realized inflation and economic growth are independent of each other and of everything else. Since bond returns depend only on news about nominal interest rates, bond returns will be deterministic on non-announcement days and their market betas will be zero. On announcement days both the market return and bond returns will respond negatively to news that future inflation will be higher than anticipated, so bond betas will be positive and increasing with maturity.

\section{Conclusion}

We show that average excess returns and Sharpe ratios on the U.S. stock market are much higher on days when important macroeconomic news is scheduled to be announced. This difference is especially pronounced at times of high risk. We also find that returns on 30-day T-bills, our measure of the risk-free rate, are significantly lower on these days. For longerterm Treasury securities, which are not riskless assets at a daily horizon, we find that the difference between announcement and non-announcement day returns uniformly increases with a bond's maturity and is positive for bonds with maturities of five years or more. Bonds comove much more with the stock market on announcement days, and this tendency also monotonically increases with maturity.

Our results demonstrate a clear link between macroeconomic risk and financial asset returns. Investors seem to require higher expected returns on risky assets as a compensation for bearing risks associated with macroeconomic news. In addition, the risk premium on non-announcement days appears to be very low, with our numbers implying that over $60 \%$ of the cumulative annual excess return for the stock market is earned on announcement days.

Our findings on risk-free rates are consistent with precautionary saving. If aggregate risk 
is higher on announcement days, then investors who care about daily changes in their wealth will seek to save more out of current wealth on those days relative to other days. To our knowledge, this is some of the first evidence of precautionary saving affecting asset prices.

These results are consistent with a simple equilibrium model of economy-wide risk that varies deterministically over time because of pre-scheduled announcements. This model can reconcile the large increase in stock market risk premia with the relatively small increase in stock market variance that we estimate. Because investors learn more about future economic conditions around announcements, they should be less willing to hold assets, such as stocks, that covary positively with these news, even if the variance of their returns is itself not much higher. If such shocks are persistent, even a small increase in their volatility (the news arrival rate) around announcements can result in large increases in the market risk premium. A reasonable calibration of our model produces risk premia and volatilities that match our empirical results. We also provide direct evidence that investors learn more about future consumption growth on announcement days, though this finding is only significant in the second half of our sample. 


\section{Appendix. Proposition Derivations}

\section{A.1. Proof of Equations (6), (7) and (8)}

For a representative investor with Epstein-Zin preferences, the stochastic discount factor is given by

$$
m_{t+1}=\ln M_{t+1}=\theta \ln \beta-\frac{\theta}{\psi} \Delta d_{t+1}-(1-\theta) r_{M K T, t+1},
$$

where $r_{M K T}$ is the log return on the market portfolio, defined as the claim to aggregate dividends in perpetuity, and $\theta=(1-\gamma) /(1-(1 / \psi))$.

Since everything is log-normal, the log return on any asset $r_{j, t+1}$ is then given by

$$
E_{t}\left[m_{t+1}+r_{j, t+1}\right]+\frac{1}{2} \operatorname{Var}_{t}\left[m_{t+1}+r_{j, t+1}\right]=0
$$

In order to solve the model, we use the Campbell-Shiller approximation for the log return on the market portfolio

$$
r_{M K T, t+1} \approx k+\Delta d_{t+1}+\rho\left(p_{t+1}-d_{t+1}\right)-\left(p_{t}-d_{t}\right),
$$

where $k$ is an unimportant constant and $\rho=(1+\exp (\overline{d-p}))^{-1}$ is another constant that is slightly less than one. We assume that announcements are not spaced through our sample in such a way that the mean log dividend-price ratio is badly defined. A sufficient condition is that announcements are regularly spaced, so that in any long period, such as one year, there is a fixed number.

Next we assume that the log aggregate price-dividend ratio is linear in the drift term $\mu_{t}$ and its intercept is a deterministic function of time:

$$
p_{t}-d_{t}=a_{0, t}+a_{1} \mu_{t}
$$

As in Bansal and Yaron (2004), $a_{1}$ is positive and the price-dividend ratio is increasing 
in expected dividend growth if and only if $\psi>1$, so that the direct effect on wealth through increased growth more than offsets the indirect effect through a higher discount rate due to higher expected growth.

The solution implies that the stochastic discount factor is given by

$$
m_{t+1}=-\delta_{t+1}-\frac{1}{\psi} \mu_{t}-\gamma v_{d, t+1}-\left(\gamma-\frac{1}{\psi}\right) \frac{\rho}{1-\rho \phi} v_{\mu, t+1},
$$

where

$$
\delta_{t+1}=-\ln \beta-(1-\gamma)\left(\gamma-\frac{1}{\psi}\right) \frac{1}{2} \operatorname{Var}_{t}\left[\nu_{d, t+1}+\frac{\rho}{1-\rho \phi} v_{\mu, t+1}\right]
$$

Iterating (A-4) forward one period gives

$$
p_{t+1}-d_{t+1}=a_{0, t+1}+a_{1} \mu_{t+1}
$$

Plugging these into the approximation (A-3) for the log market portfolio return, then plugging the derived expression into the pricing equation (A-2), given the equation for the stochastic discount factor (A-1), and equating coefficients gives:

$$
a_{1}=\frac{1-\frac{1}{\psi}}{1-\rho \phi}
$$

and

$$
a_{0, t}=b_{0}+b_{1} A_{t+1}+\rho a_{0, t+1}
$$

confirming our conjecture. Here

$$
b_{0}=\ln \beta+k+\rho a_{1}(1-\phi) \bar{\mu}-\frac{1}{2}(\gamma-1)\left(1-\frac{1}{\psi}\right)\left(\sigma_{d, L}^{2}+\left(\frac{\rho}{1-\rho \phi}\right)^{2} \sigma_{\mu, L}^{2}\right)
$$


and

$$
b_{1}=-\frac{1}{2}(\gamma-1)\left(1-\frac{1}{\psi}\right)\left(\left(\sigma_{d, H}^{2}-\sigma_{d, L}^{2}\right)+\left(\frac{\rho}{1-\rho \phi}\right)^{2}\left(\sigma_{\mu, H}^{2}-\sigma_{\mu, L}^{2}\right)\right)
$$

Assuming no rational bubbles implies

$$
\lim _{s \rightarrow \infty} \rho^{s} E_{t}\left[p_{t+s}-d_{t+s}\right]=0
$$

hence

$$
\begin{aligned}
\lim _{s \rightarrow \infty} \rho^{s} a_{0, t+s}+\lim _{s \rightarrow \infty} \rho^{s} a_{1} E_{t}\left[\mu_{t+s}\right] & =\lim _{s \rightarrow \infty} \rho^{s} a_{0, t+s}+a_{1} \bar{\mu} \lim _{s \rightarrow \infty} \rho^{s} \\
& =\lim _{s \rightarrow \infty} \rho^{s} a_{0, t+s}=0
\end{aligned}
$$

hence

$$
a_{0, t}=\frac{b_{0}}{1-\rho}+b_{1} \sum_{j=1}^{\infty} \rho^{j} A_{t+1+j}
$$

Plugging back into the approximation (A-3) gives equation (7). Equation (6) follows from substituting (7) into (A-1). Subtracting equation (6) from equation (7) gives equation (8).

\section{A.2. Derivation of nominal bond risk premia}

The price of a nominal bond is derived by conjecturing that

$$
p_{n, t}^{\$}=c_{0, t}^{n}+c_{1}^{n} \mu_{t}+c_{2}^{n} z_{t}
$$

where $c_{0, t}^{n}$ is a deterministic function of time and maturity and the other coefficients depend only on maturity. Since the log price of $\$ 1$ is zero, all coefficients equal zero at $n=0$. Since the bond's real return is $p_{n-1, t+1}^{\$}-p_{n, t}^{\$}-\pi_{t+1}$, iterating forward, plugging the conjecture into 
equation (A-2) and equating coefficients confirms the conjecture and in particular gives

$$
\begin{aligned}
c_{1}^{n} & =-\frac{1}{\psi} \frac{1-\phi^{n}}{1-\phi} \\
c_{2}^{n} & =-\frac{1-\lambda^{n}}{1-\lambda}
\end{aligned}
$$

Equations (15) and (16) follow.

\section{A.3. Changes in Stock Market Variance}

Equation (8) holds both on announcement days and non-announcement days. The difference in market risk premium $r p_{M K T, t}=\ln E_{t}\left[\left(1+R_{M K T, t+1}\right) /\left(1+R_{f, t+1}\right)\right]$ is therefore:

$$
\begin{aligned}
r p_{M K T, t}^{A}-r p_{M K T, t}^{N}= & \gamma\left(\operatorname{Var}_{t}\left[r_{M K T, t+1}^{A}\right]-\operatorname{Var}_{t}\left[r_{M K T, t+1}^{N}\right]\right) \\
& +\frac{\gamma-1}{\psi}\left(\operatorname{Cov}_{t}\left[r_{M K T, t+1}^{A}, \frac{\rho}{1-\rho \phi} \mu_{t+1}^{A}\right]-\operatorname{Cov}_{t}\left[r_{M K T, t+1}^{N}, \frac{\rho}{1-\rho \phi} \mu_{t+1}^{N}\right]\right) \\
\approx & \frac{\gamma-1}{\psi}\left(\operatorname{Cov}_{t}\left[r_{M K T, t+1}^{A}, \frac{\rho}{1-\rho \phi} \mu_{t+1}^{A}\right]-\operatorname{Cov}_{t}\left[r_{M K T, t+1}^{N}, \frac{\rho}{1-\rho \phi} \mu_{t+1}^{N}\right]\right)
\end{aligned}
$$

The approximation follows because the difference in variance of stock market returns be-

tween announcement and non-announcement days is negligible, so that $\sigma_{M K T, t}^{A}=\sqrt{\operatorname{Var}_{t}\left[r_{M K T, t+1}^{A}\right]} \approx$ $\sigma_{M K T, t}^{N}=\sigma_{M K T, t}$.

Now assume (for simplicity) that the correlation $\rho_{M K T, \mu}$ is constant and does not vary across days. Defining $\sigma_{\mu, t}^{2}=\operatorname{Var}_{t}\left[\mu_{t+1}\right]$,

$$
r p_{M K T, t}^{A}-r p_{M K T, t}^{N}=\frac{\gamma-1}{\psi} \rho_{M K T, \mu} \sigma_{M K T, t}\left(\sigma_{\mu, t}^{A}-\sigma_{\mu, t}^{N}\right)
$$

which is increasing in $\sigma_{M K T, t}^{2}$.

\section{A.4. Stock Market Implied Volatility}

Our model has implications for Black-Scholes implied volatilities, such as the CBOE's (old) Vix index. Under the assumptions of the Black-Scholes model, the square of the implied 
volatility of a $\tau$-day option (assuming no dividends are paid between dates $t$ and $t+\tau$ ) is the conditional variance of the $\log \tau$-day ahead price $p_{t+\tau}$ :

$$
\sigma_{\tau, B S}^{2}=\operatorname{Var}_{t}\left[\ln P_{t+\tau}\right]=\operatorname{Var}_{t}\left[p_{t+\tau}\right]
$$

Since

$$
p_{t+\tau}=\left(p_{t+\tau}-d_{t+\tau}\right)+d_{t+\tau}
$$

the Black-Scholes implied variance is approximately

$$
\sigma_{B S, t}^{\tau 2} \approx\left(\frac{1-\frac{1}{\psi}}{1-\rho \phi}\right)^{2} \operatorname{Var}_{t}\left[\sum_{j=1}^{\tau} \phi^{\tau-j} \nu_{\mu, t+j}\right]+\operatorname{Var}_{t}\left[\sum_{j=1}^{\tau} \nu_{d, t+j}\right]
$$

The model-implied change in the square of constant-maturity Black-Scholes implied volatility from the day prior to an announcement to the end of the following day is therefore

$\Delta \sigma_{B S, t+1}^{\tau 2}=\left(\sigma_{d, H}^{2}-\sigma_{d, L}^{2}\right)\left(A_{t+1+\tau}-A_{t+1}\right)+\left(\sigma_{\mu, H}^{2}-\sigma_{\mu, L}^{2}\right)\left(\frac{1-\frac{1}{\psi}}{1-\rho \phi}\right)^{2} \sum_{j=1}^{\tau}\left(\phi^{\tau-j}\right)^{2}\left(A_{t+1+j}-A_{t+j}\right)$,

where $\tau$ is the number of days until expiration of the options from whose prices the implied volatility is derived. In the case of Vix, $\tau$ is standardized to 30 days and is quoted on an annualized basis, so will change by $(365 / 30) \Delta \sigma_{B S, t+1}^{\tau 2}$ from date $t$ to date $t+1$.

This change consists of two terms. First, if date $t+1$ is an announcement day and date $t+31$ is not, then squared implied volatility will decline by an amount equal to the increase in variance of dividend growth around announcement days. Intuitively, one can think of Vix as a "portfolio" of 30 individual daily implied volatilities, so when a high volatility day is replaced by a low volatility one, this term of Vix should drop by $\sigma_{d, H}^{2}-\sigma_{d, L}^{2}$.

The second term is more complex, since it depends not only on the day added and the day subtracted, but also on the intervening days. Since the persistence of shocks to expected 
growth is less than one, the impact of announcements today on the conditional variance of $\mu_{t+\tau}$ will be smaller than the impact of an announcement later in the next 30 days. In particular, if $A_{t+31}$ is also an announcement day, this second term in Vix could actually increase by a small amount at date $t+1$. However, $A_{t+31}=1$ and $A_{t+j}=0$ for $j=2 \ldots 30$ maximizes the increase in this second term for any value of $\phi$. Furthermore, the second highest value, if $A_{t+31}$ is zero, is negative for any value of $\phi$. Thus, provided we assume $A_{t+31}=0$ for all dates $t$, the model predicts a drop in Vix from before to after announcements. This assumption, if false, biases against our finding the results we report in the paper. 


\section{References}

Andersen, T. G.; T. Bollerslev; F. X. Diebold; and C. Vega. "Real-time Price Discovery in Stock, Bond and Foreign Exchange Markets." Journal of International Economics, 73 (2007), $251-277$.

Ariel, R. A. "A Monthly Effect in Stock Returns." Journal of Financial Economics, 19 (1987), $161-174$.

Ariel, R. A. "High Stock Returns Before Holidays: Existence and Evidence on Possible Causes." Journal of Finance, 45 (1990), 1611-1626.

Balduzzi, P.; E. J. Elton; and T. C. Green "Economic News and Bond Prices: Evidence From the U.S. Treasury Market." Journal of Financial and Quantitative Analysis, 36 (2001), $523-543$.

Ball, R., and S. P. Kothari, "Security Returns around Earnings Announcements." Accounting Review, 66 (1991), 718-738.

Bansal, R.; V. Khatacharian; and A. Yaron "Interpretable Asset Markets?" European Economic Review, 49 (2005), 531-560.

Bansal, R.; T. Tallarini; and A. Yaron "The Return to Wealth, Asset Pricing, and the Intertemporal Elasticity of Substitution." working paper (2008).

Bansal, R., and A. Yaron "Risks for the Long Run: A Potential Resolution of Asset Pricing Puzzles." Journal of Finance, 59 (2004), 1481-1509.

Beaver, W. H. "The Information Content of Annual Earnings Announcements.", Journal of Accounting Research, 6 (1968), 67-92.

Beber, A. and M. W. Brandt "Resolving Macroeconomic Uncertainty in Stock and Bond Markets." Review of Finance, 13 (2009), 1-45.

Bernanke, B. S., and K. N. Kuttner "What Explains the Stock Market's Reaction to Federal Reserve Policy?" Journal of Finance, 60 (2005), 1221-1257.

Bertaut, C. and M. Starr-McCluer "Household Portfolios in the United States." Federal Reserve Board discussion paper (2000). 
Bodie, Z. "Common Stocks as a Hedge Against Inflation." Journal of Finance, 31 (1976), $459-470$.

Bomfim, A. N. "Pre-announcement Effects, News Effects and Volatility: Monetary Policy and the Stock Market." Journal of Banking and Finance, 27 (2003), 133-151.

Boyd, J. H.; J. Hu; and R. Jagannathan "The Stock Market's Reaction to Unemployment News: Why Bad News is Usually Good for Stocks." Journal of Finance, 60 (2005), 649-672. Brenner, M.; P. Pasquariello; and M. Subrahmanyam "On the Volatility and Comovement of U.S. Financial Markets Around Macroeconomic News Announcements." Journal of Financial and Quantitative Analysis, 44 (2009), 1265-1289.

Buraschi, A., and A. Jiltsov "Habit Formation and the Term Structure of Interest Rates." Journal of Finance, 62 (2007), 3009-3063.

Campbell, J.. Y.; M. Lettau; B. G. Malkiel; and Y. Xu "Have Individual Stocks Become More Volatile? An Empirical Exploration of Idiosyncratic Risk." Journal of Finance, 56 (2001), 1-43.

Campbell, J. Y.; A. Sunderam; and L. M. Viceira "Inflation Bets or Deflation Hedges? The Changing Risks of Nominal Bonds." Harvard University working paper (2011).

Campbell, J. Y., and L. Viceira Strategic Asset Allocation, Oxford University Press (2002). Campbell, J. Y., and T. Vuolteenaho "Inflation Illusion and Stock Prices." American Economic Review, 94 (2004), 19-23.

Chari, V. V.; R. Jagannathan; and A. R. Ofer "Seasonalities in Security Returns: The Case of Earnings Announcements." Journal of Financial Economics, 21 (1988), 101-121.

Cohen, D. A.; A. Dey; T. Z. Lys; and S. V. Sunder "Earnings Announcement Premia and the Limits to Arbitrage." Journal of Accounting and Economics, 43 (2007), 153-180.

Cutler, D. M.; J. M. Poterba; and L. H. Summers "What Moves Stock Prices?" Journal of Portfolio Management, 15 (1989), 4-12.

Dubinsky, A., and M. Johannes "Earnings Announcements and Equity Options." Columbia University working paper (2005). 
Ederington, L. H., and J. H. Lee "The Creation and Resolution of Market Uncertainty: The Impact of Information Releases on Implied Volatility." Journal of Financial and Quantitative Analysis, 31 (1996), 513-539.

Fama, E. F. "Stock Returns, Real Activity, Inflation, and Money." American Economic Review, 71 (1987), 545-565.

Fama, E. F., and G. W. Schwert "Asset Returns and Inflation." Journal of Financial Economics, 4 (1977), 115-146.

Flannery, M. J., and A. A. Protopapadakis "From T-bills to Common Stocks: Investigating the Generality of Intra-week Return Seasonality." Journal of Finance, 43 (1988), 431-450.

Flannery, M. J., and A. A. Protopapadakis "Macroeconomic Factors Do Inłuence Aggregate Stock Returns." Review of Financial Studies, 15 (2002), 751-782.

Fleming, M. J., and E. M. Remolona "What Moves the Bond Market?" Federal Reserve Bank of New York Economic Policy Review, 3 (1997), 31-50.

Frazzini, A., and O. Lamont "The Earnings Announcement Premium and Trading Volume." NBER Working Paper 13090 (2007).

French, K. "Stock Returns and the Weekend Effect." Journal of Financial Economics, 8 (1980), 55-70.

French, K.; R. Leftwich; and W. Uhrig "The Effect of Scheduled Announcements on Futures Markets." University of Chicago working paper (1989).

Geske, R., and R. Roll "The Fiscal and Monetary Linkage Between Stock Returns and Inflation." Journal of Finance, 38 (1983), 1-33.

Gibbons, M. R. and P. Hess "Day of the Week Effects and Asset Returns." Journal of Business, 54 (1981), 579-596.

Gurkaynak, R. S.; B. Sack; and E. Swanson "The Sensitivity of Long-term Interest Rates to Economic News: Evidence and Implications for Macroeconomic Models." American Economic Review, 95 (2005), 425-436.

Hardouvelis, G. A. "Macroeconomic Information and Stock Prices." Journal of Economics 
and Business, 39 (1987), 131-140.

Hong, H.; J. D. Kubik; and J. C. Stein "Social Interaction and Stock Market Participation." Journal of Finance, 59 (2004), 137-163.

Jaffe, J. F.., and G. Mandelker "Inflation and the Holding Period Returns on Bonds." Journal of Financial and Quantitative Analysis, 14 (1979), 959-979.

Jones, C. M.; O. Lamont; and R. L. Lumsdaine "Macroeconomic News and Bond Market Volatility." Journal of Financial Economics, 47 (1998), 315-337.

Kalay, A., and U. Loewenstein "Predictable Events and Excess Returns: the Case of Dividend Announcements." Journal of Financial Economics, 14 (1985), 423-449.

Knight, F. H. "Risk, Uncertainty and Profit." (Houghton Mifflin Co) (1921).

Krueger, A. B. "Do Markets Respond More to Reliable Labor Market Data? A Test of Market Rationality." NBER working paper 5769 (1996).

Kuttner, K. N. "Monetary Policy Surprises and Interest Rates: Evidence from the Fed Funds Futures Market." Journal of Monetary Economics, 47 (2001), 523-544.

Lakonishok, J., and S. Smidt "Are Seasonal Anomalies Real? A Ninety-year Perspective." Review of Financial Studies, 1 (1988), 403-425.

Lettau, M., and S. C. Ludvigson "Measuring and Modelling Variation in the Risk-Return Tradeoff." in Yacine Ait-Sahalia and Lars Peter Hansen, ed.: Handbook of Financial Econometrics (North-Holland, Holland) (2007).

Li, L., and R. Engle "Macroeconomic Announcements and Volatility of Treasury Futures." University of California, San Diego working paper (1998).

Mankiw, N. G., and S. Zeldes "The Consumption of Stockholders and Non-stockholders." Journal of Financial Economics, 29 (1991), 97-112.

McQueen, G., and V. V. Roley "Stock Prices, News, and Business Conditions." Review of Financial Studies, 6 (1993), 683-707.

Merton, R. C. "An Intertemporal Capital Asset Pricing Model." Econometrica, 41 (1973), $867-887$. 
Modigliani, F., and R. Cohn "Inflation, Rational Valuation and the Market." Financial Analysts Journal, 37 (1979), 24-44.

Nelson, C. R. "Inflation and Rates of Return on Common Stocks." Journal of Finance, 31 (1976), 471-483.

Nelson, C. R., and G. W. Schwert "Short-term Interest Rates as Predictors of Inflation: On

Testing the Hypothesis that the Real Rate of Interest is Constant." American Economic Review, 67 (1977), 478-486.

Orphanides, A. "When Good News is Bad News: Macroeconomic News and the Stock Market." Board of Governors of the Federal Reserve System (1992).

Parker, J. A. "The Consumption Risk of the Stock Market." Brookings Papers on Economic Activity, 32 (2001), 279-348.

Pearce, D. K., and V. V. Roley "The Reaction of Stock Prices to Unanticipated Changes in Money: A Note." Journal of Finance, 38 (1983), 1323-1333.

Pearce, D. K., and V. V. Roley "Stock Prices and Economic News." Journal of Business, 58 (1985), 49-67.

Pollet, J. M., and M. Wilson "Average Correlation and Stock Market Returns." Journal of Financial Economics, 96 (2010), 364-380.

Savor, P., and M. Wilson "Earnings Announcements and Systematic Risk." working paper (2011).

Schwert, G. W. "The Adjustment of Stock Prices to Information About Inflation." Journal of Finance, 36 (1981), 15-29.

Skiadas, C. "Smooth Ambiguity Aversion Toward Small Risks and Continuous-time Recursive Utility." Northwestern University working paper (2008).

Stock, J. H., and M.. W. Watson "Why Has Inflation Become Harder to Forecast?" Journal of Money, Credit, and Banking, 39 (2007), 3-34.

Vissing-Jorgenson, A. "Limited Asset Market Participation and the Elasticity of Intertemporal Substitution." Journal of Political Economy, 110 (2002), 825-853. 
Wilcox, D. W. "The Construction of U.S. Consumption Data: Some Facts and Their Implications for Empirical Work." American Economic Review, 82 (1992), 922-941. 


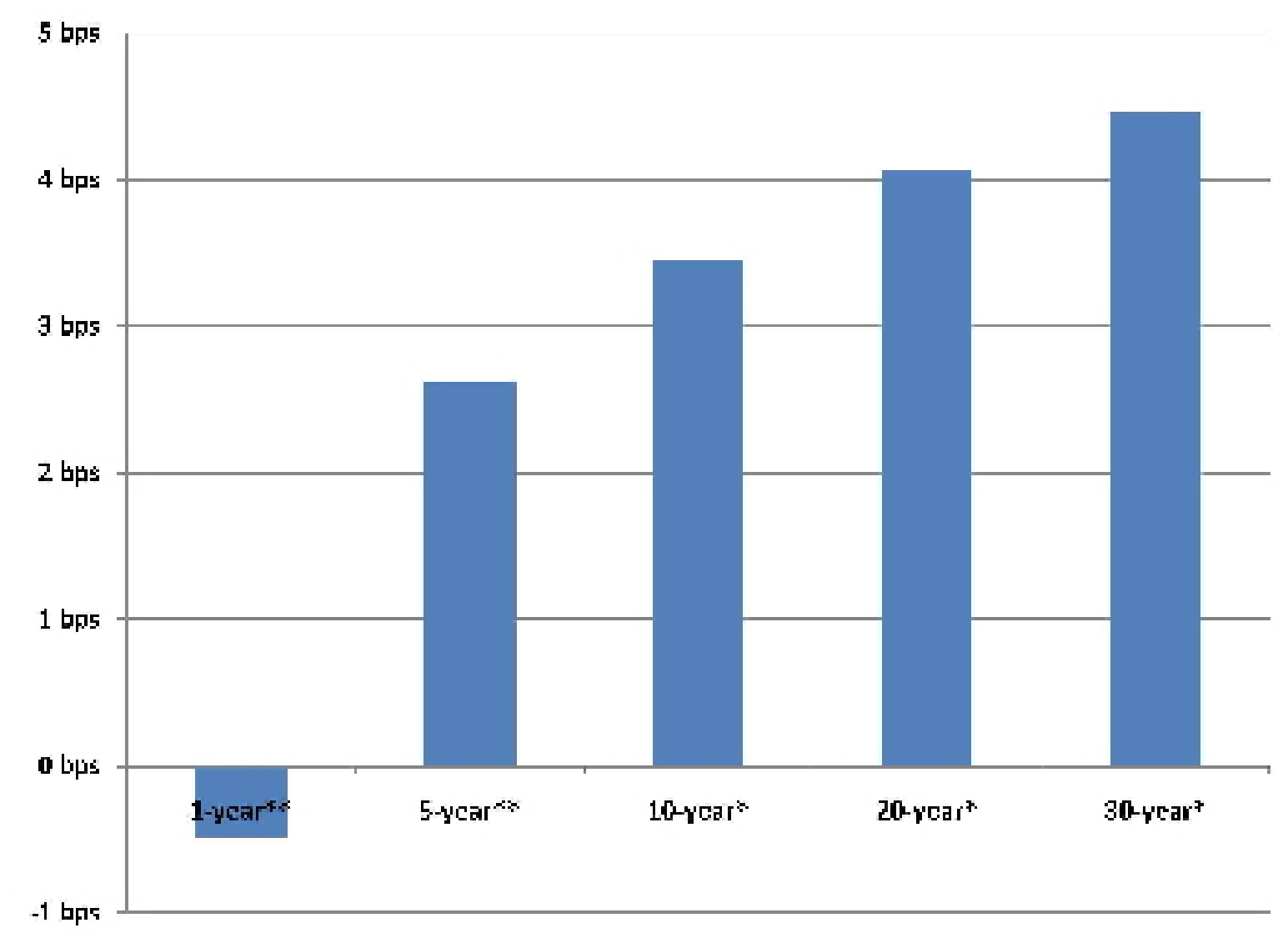

Figure 1. The Difference between Announcement Day and Non-announcement Day Treasury Bond Excess Returns. The chart plots the difference between the mean announcement day excess return and the mean excess return on other days for Treasury bonds of different maturities. Treasury bond returns are obtained from the CRSP Fixed Term Indices File. The difference is expressed in basis points (bps). ${ }^{*}$ and ${ }^{* *}$ indicate statistical significance at the $5 \%$ and $1 \%$ levels respectively. 


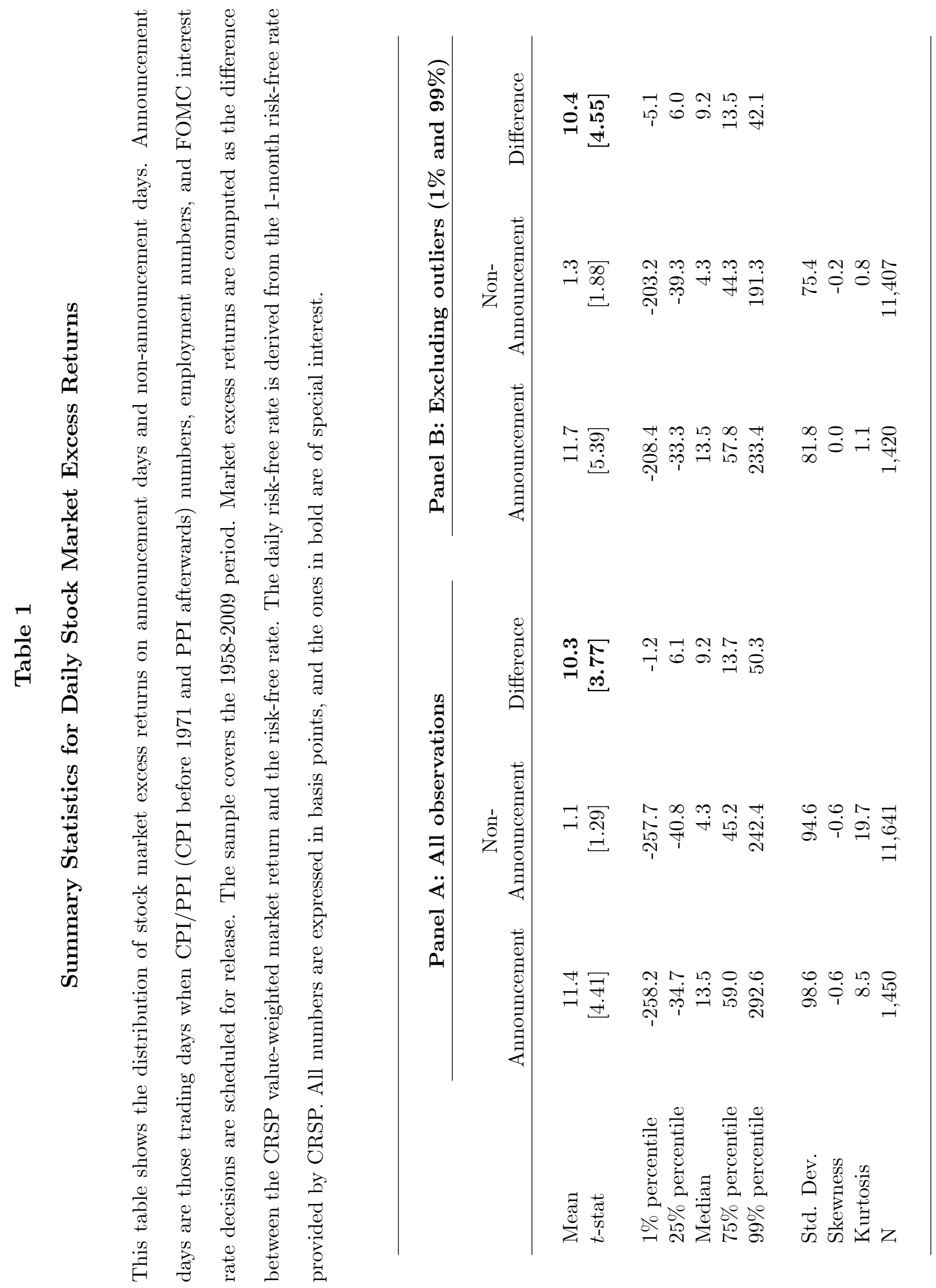




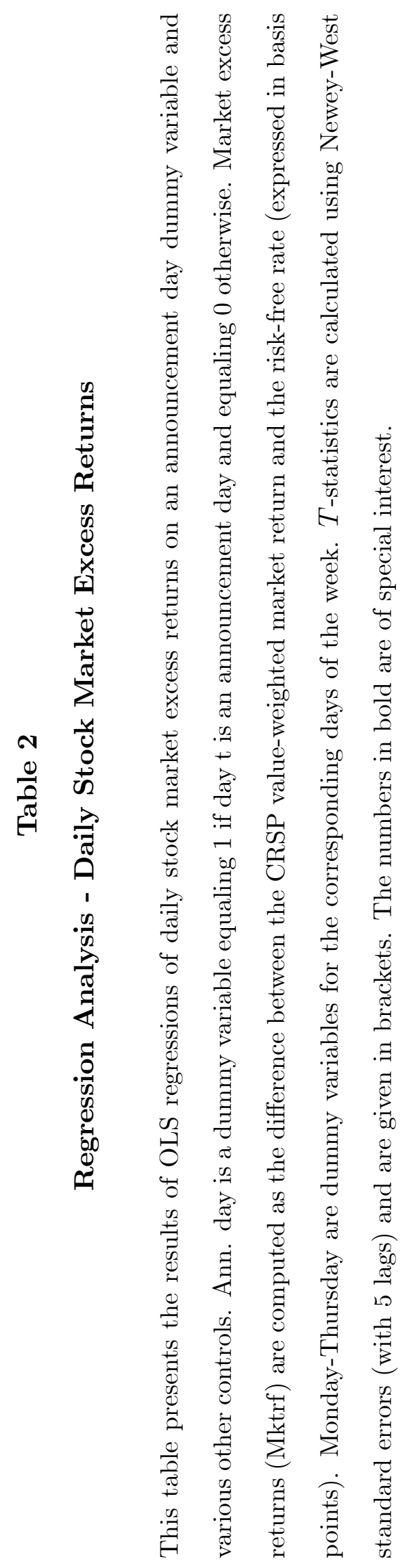




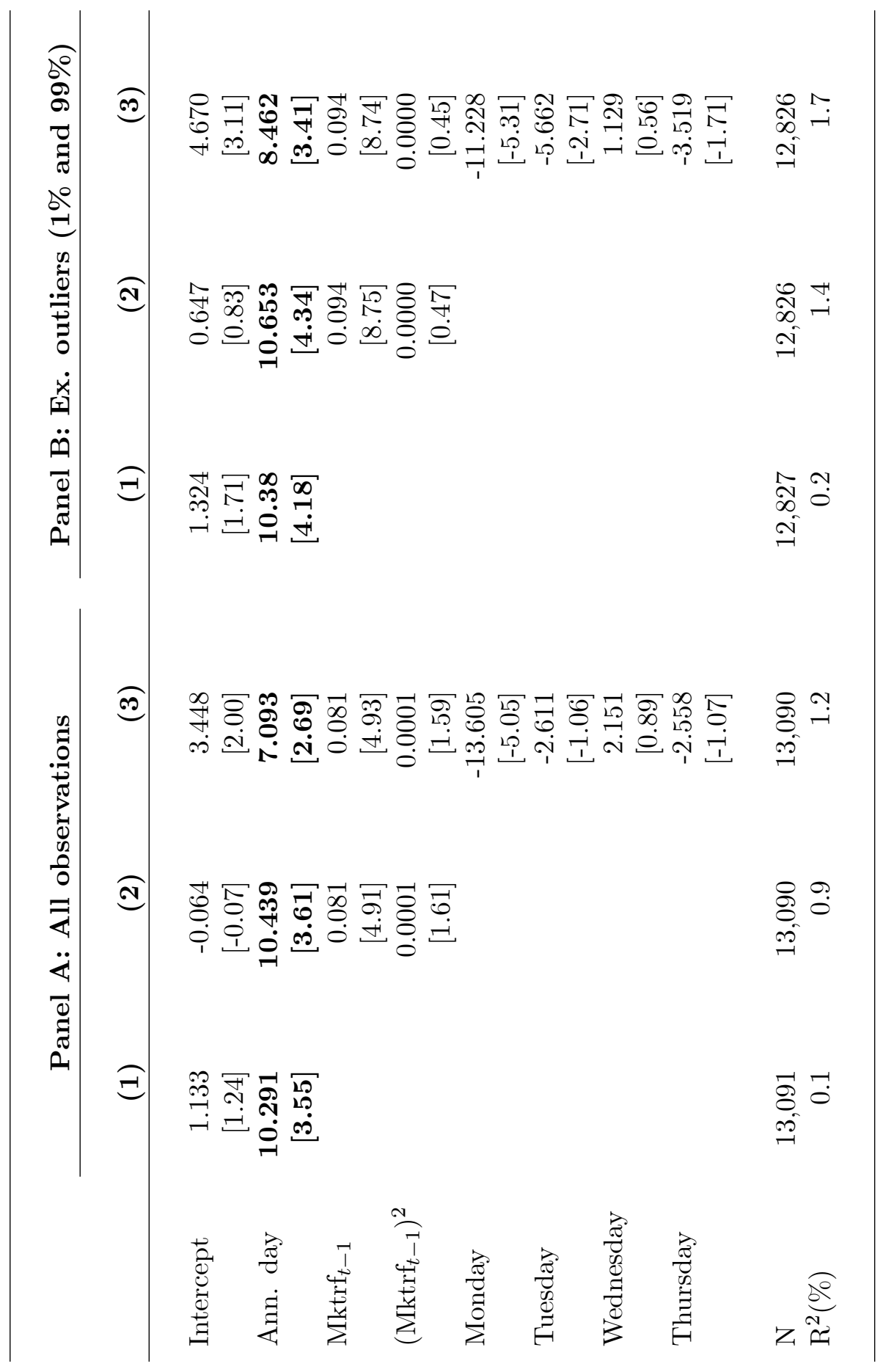




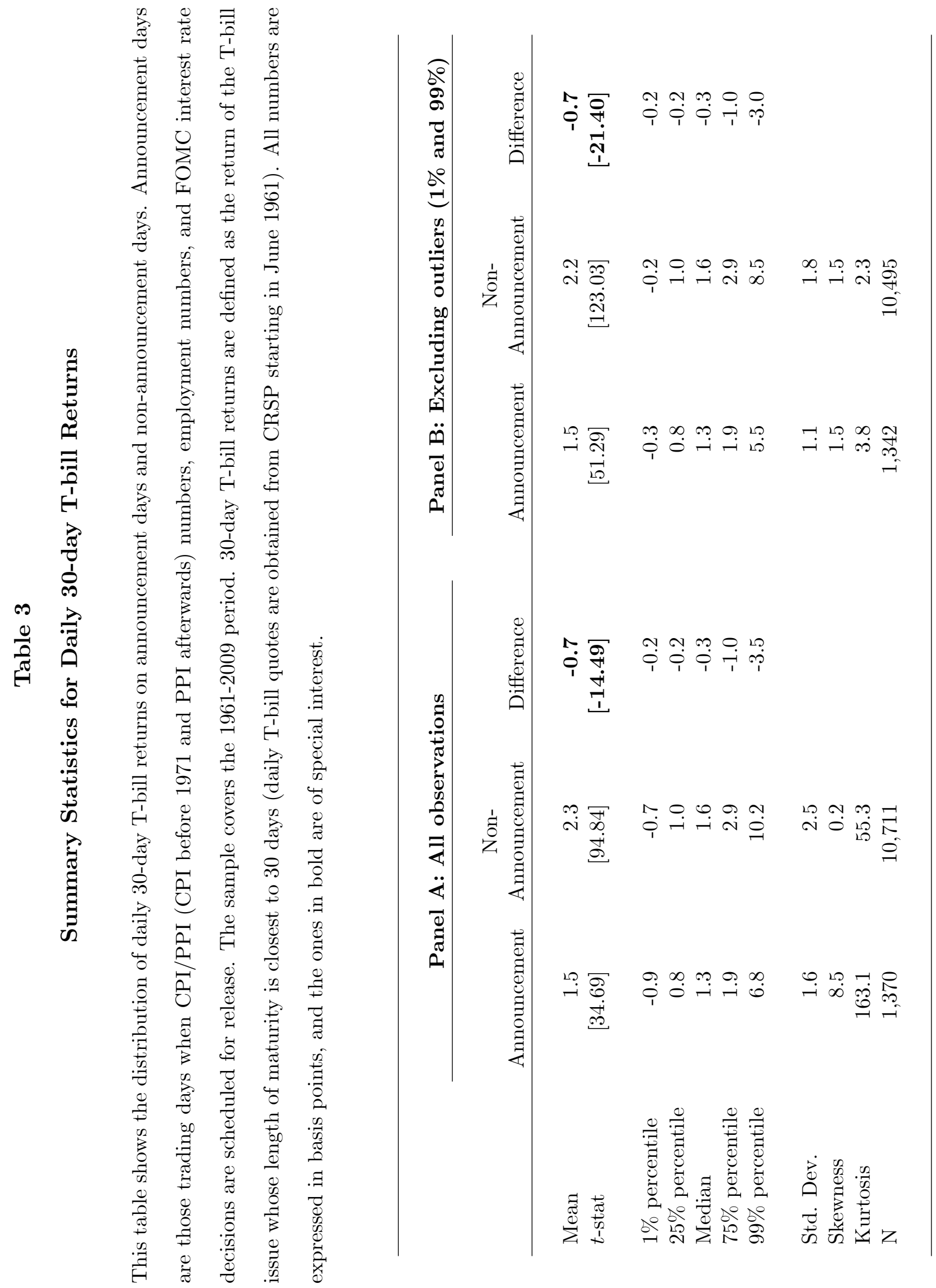




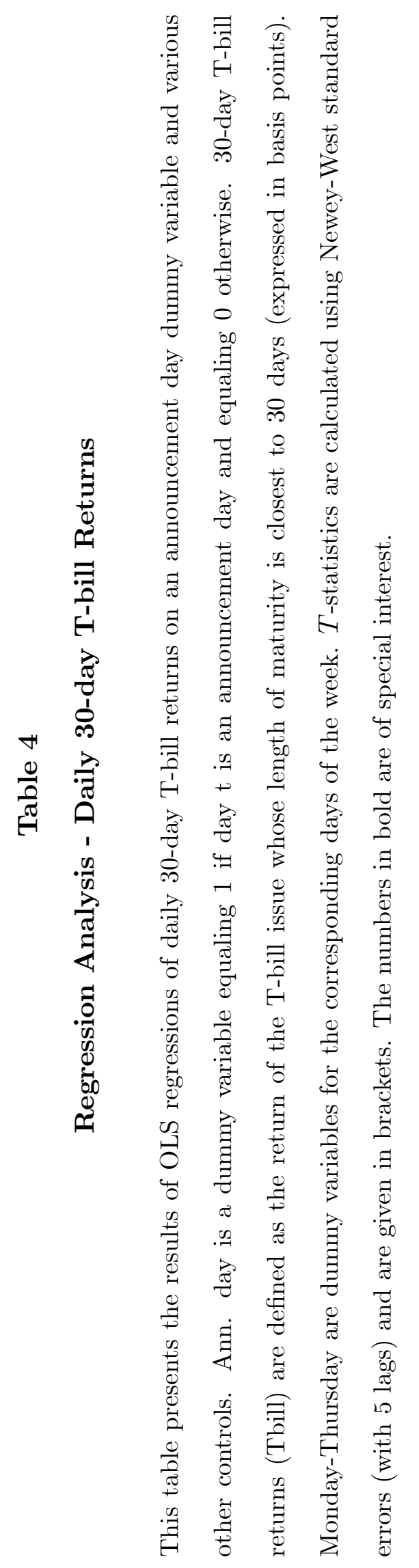




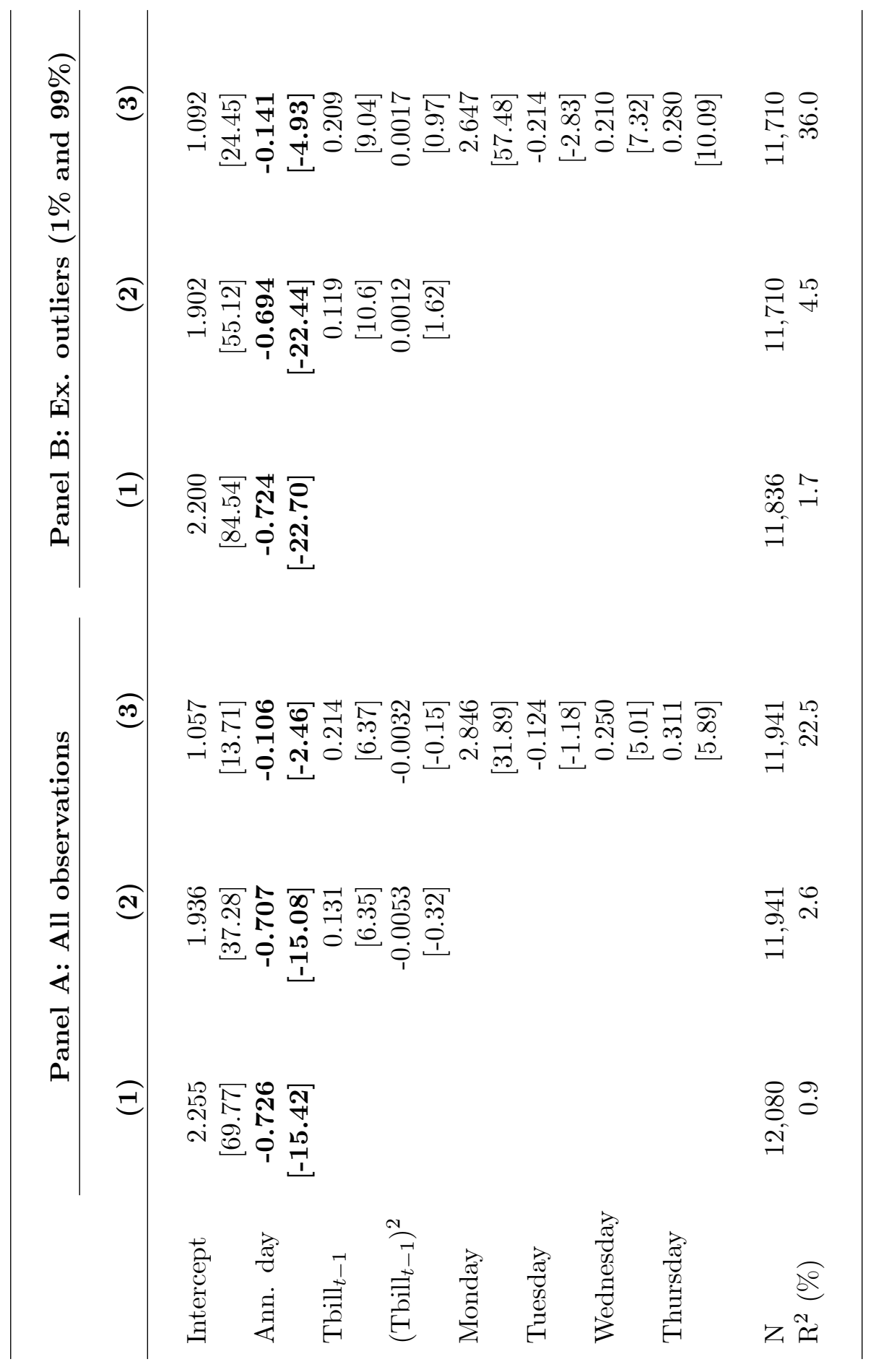




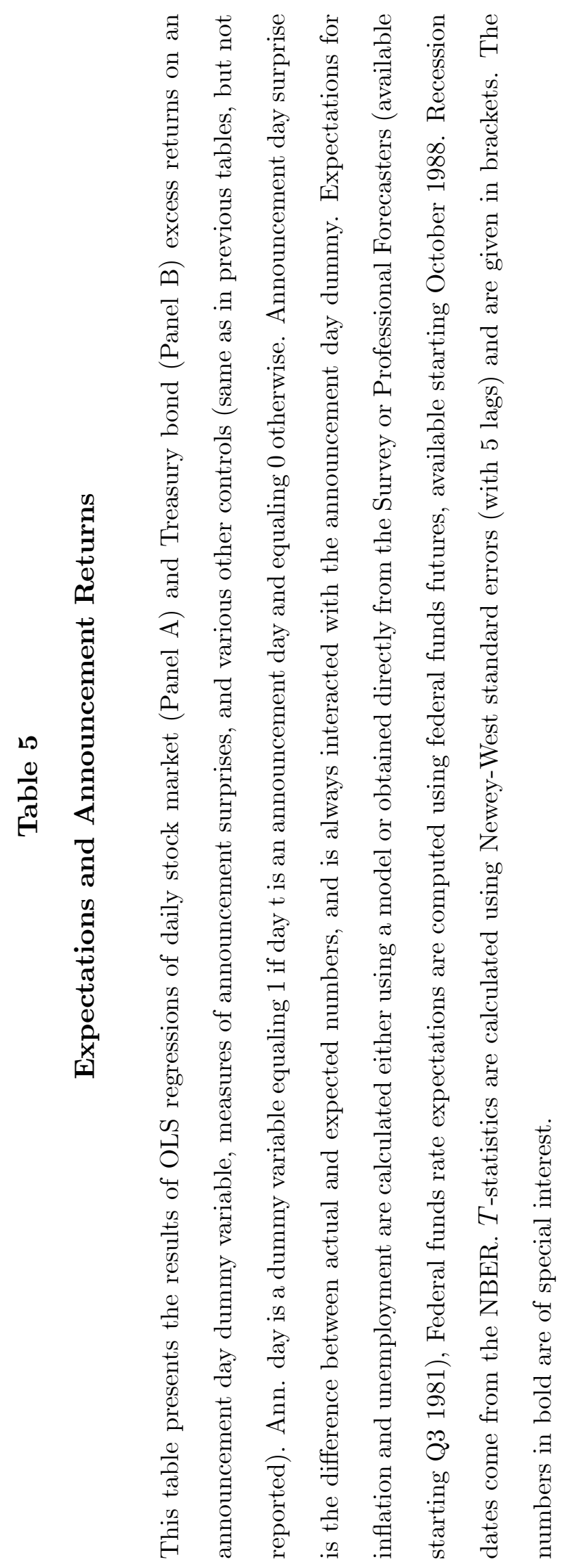




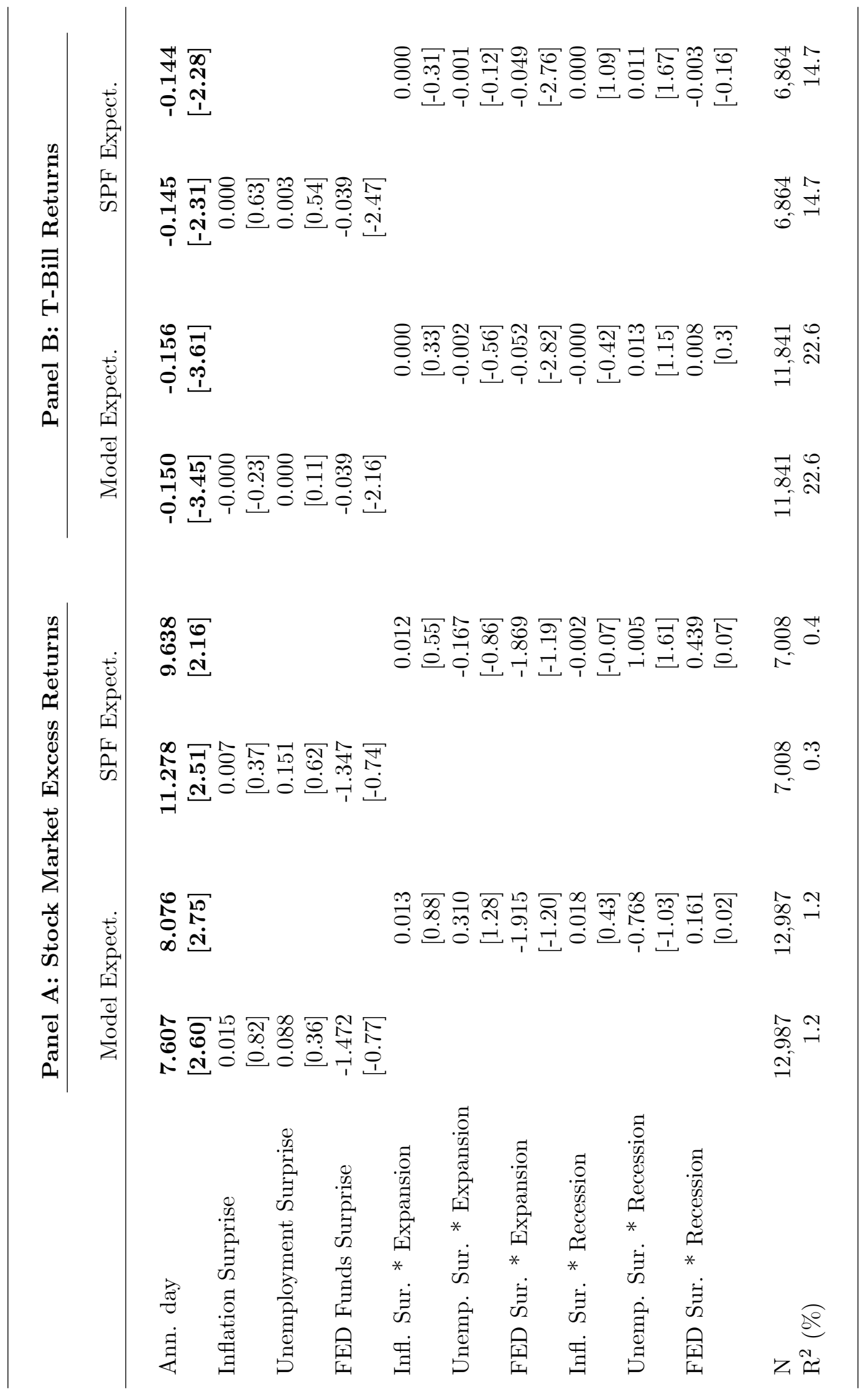




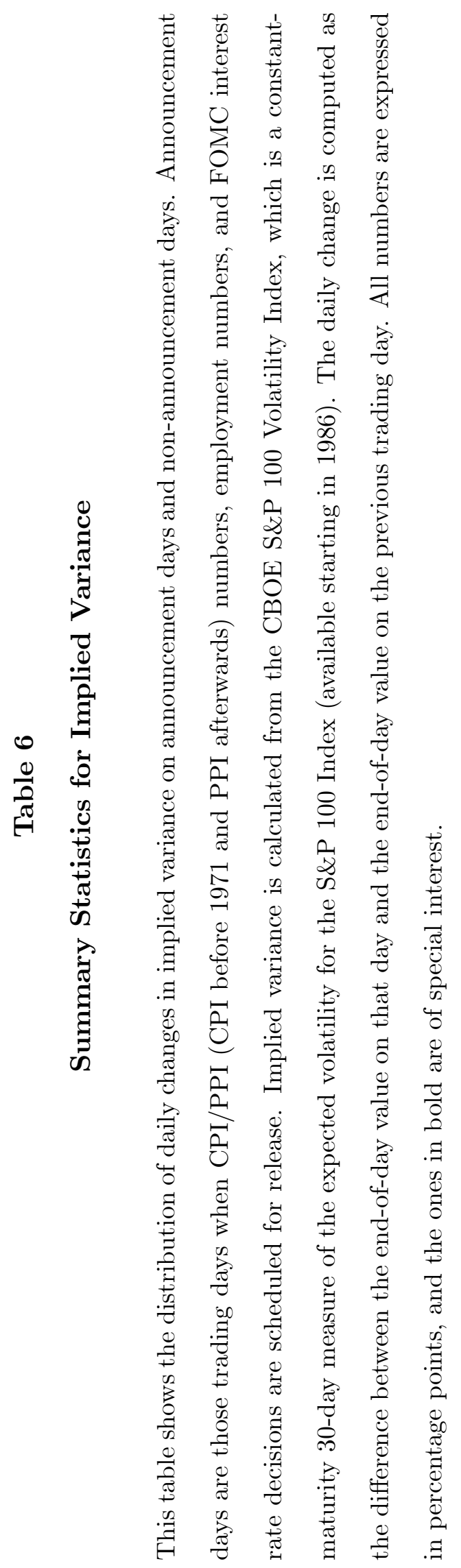




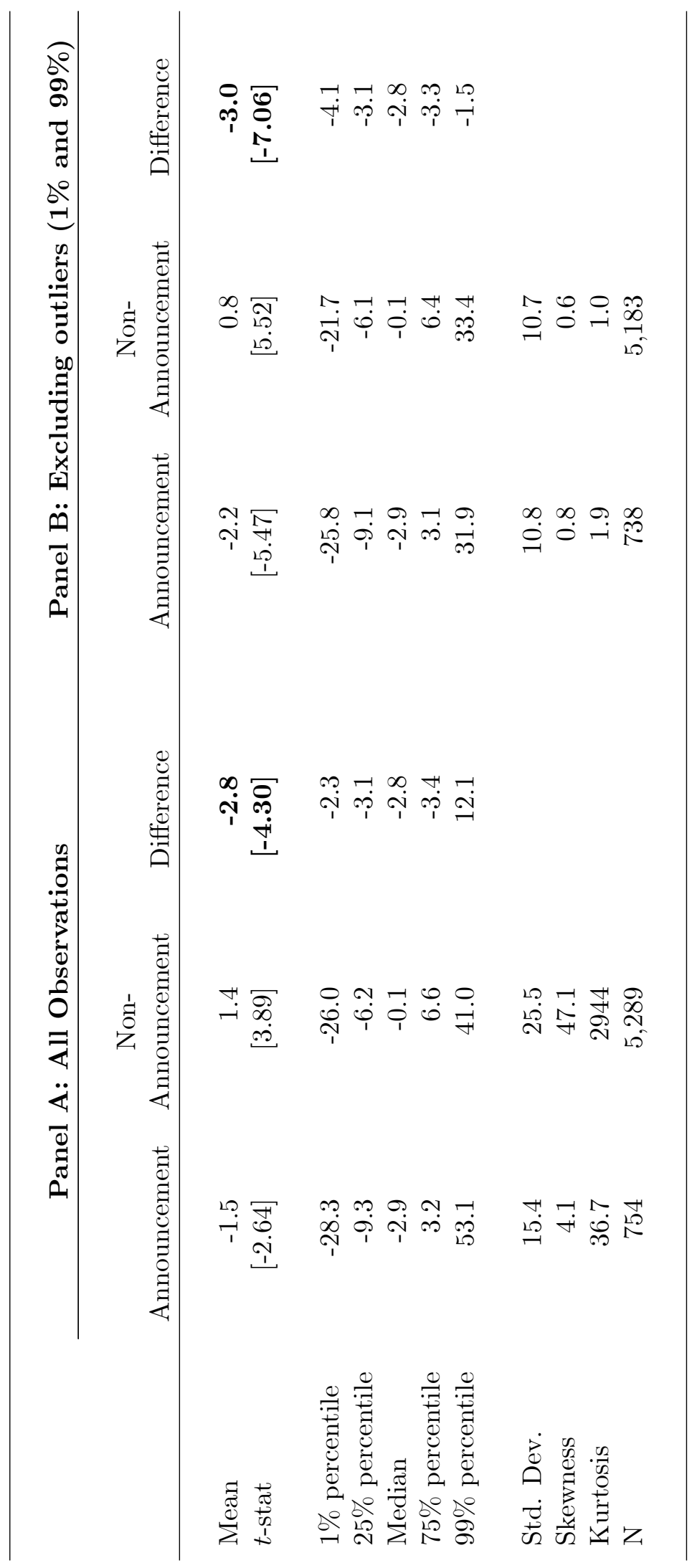




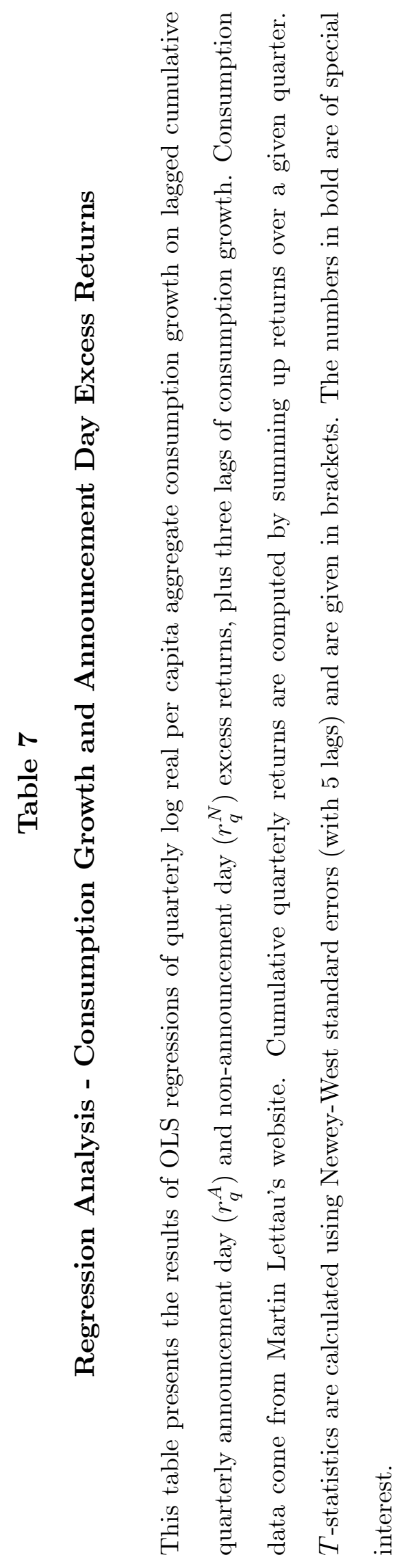




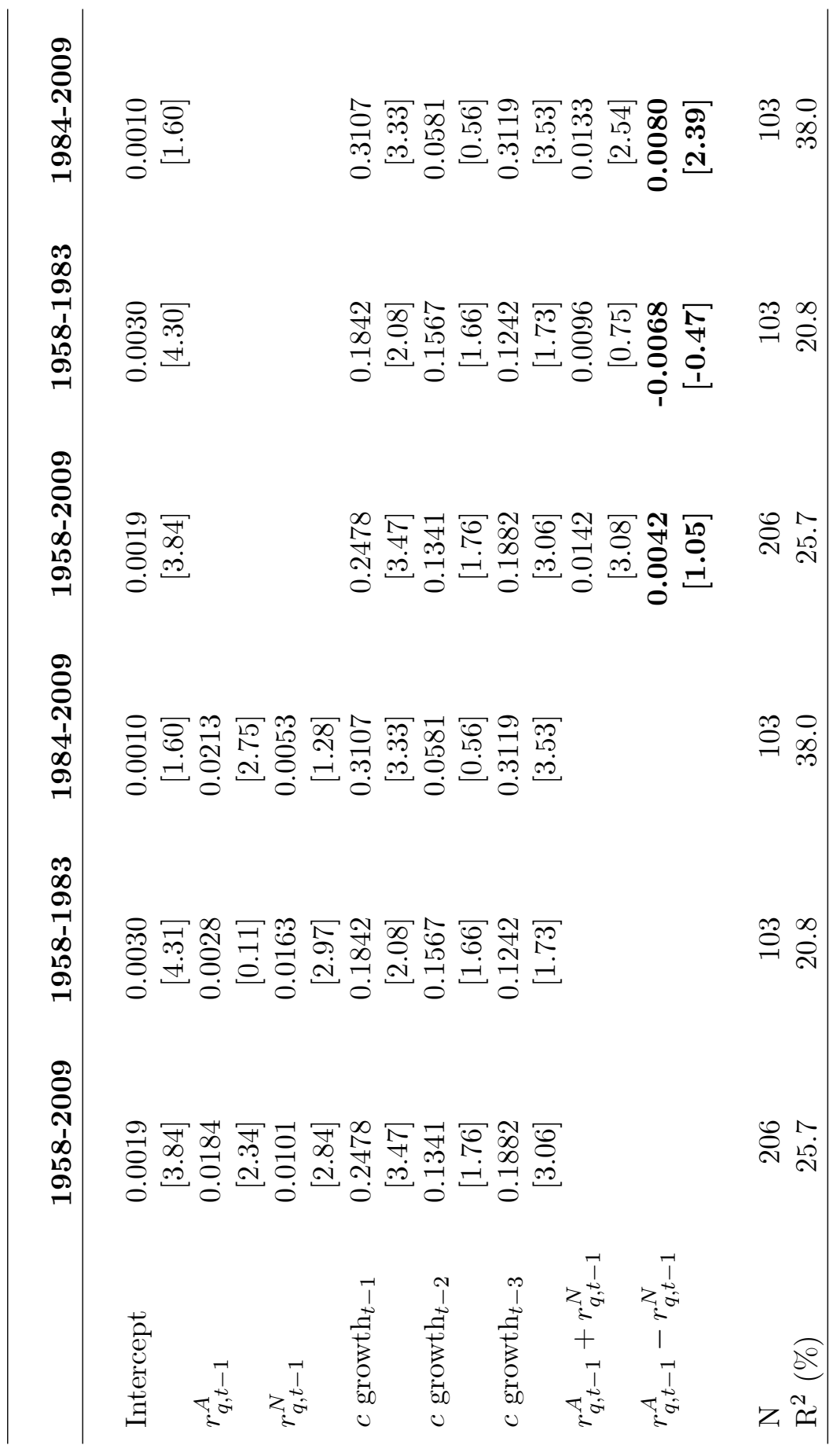




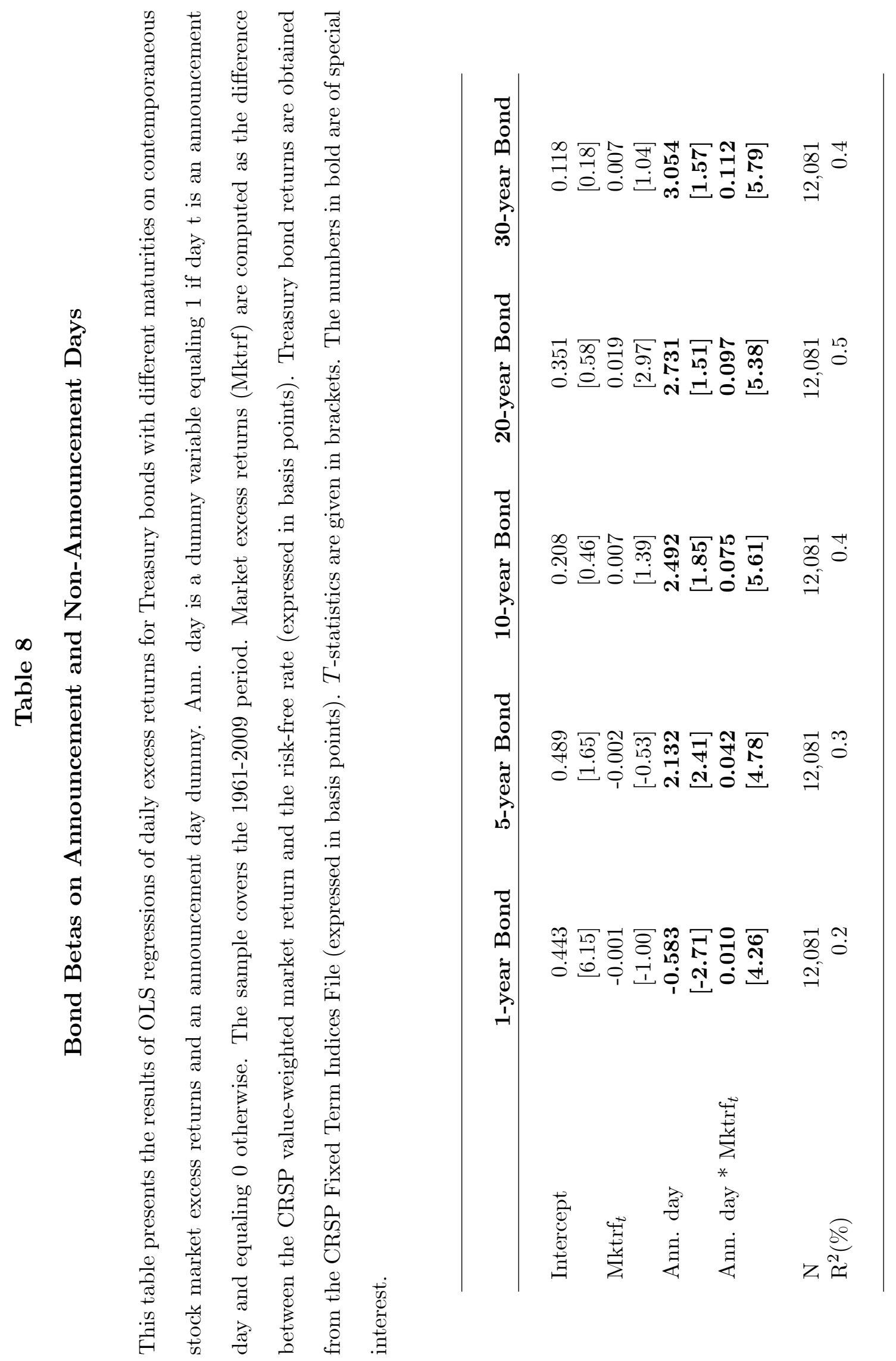

